\title{
AN EXPLORATORY INVESTIGATION OF PUBLIC PERCEPTIONS TOWARDS SAFETY AND SECURITY FROM THE FUTURE USE OF FLYING CARS IN THE UNITED STATES
}

By

\author{
Ugur Eker \\ Graduate Research Assistant \\ Department of Civil, Structural, and Environmental Engineering \\ Engineering Statistics and Econometrics Application Research Laboratory \\ University at Buffalo, The State University of New York \\ ugureker@buffalo.edu \\ Sheikh Shahriar Ahmed \\ Graduate Research Assistant \\ Department of Civil, Structural and Environmental Engineering \\ Engineering Statistics and Econometrics Application Research Laboratory \\ University at Buffalo, The State University of New York \\ sheikhsh@buffalo.edu \\ Grigorios Fountas, Ph.D. \\ Lecturer \\ Transport Research Institute \\ School of Engineering and the Built Environment \\ Edinburgh Napier University \\ 10 Colinton Road, Edinburgh, EH10 5DT, UK \\ G.Fountas@napier.ac.uk
}

And

Panagiotis Ch. Anastasopoulos, Ph.D.

Assoc. Professor and Stephen E. Still Chair of Transportation Engineering Department of Civil, Structural and Environmental Engineering Stephen Still Institute for Sustainable Transportation and Logistics

University at Buffalo, The State University of New York panastas@buffalo.edu

Revision submitted in

July, 2019 


\section{ABSTRACT}

This study aims at investigating public perceptions towards the safety and security implications that will arise after the future introduction of flying cars in the traffic fleet. In this context, we focus on individuals’ opinions about possible safety benefits and concerns as well as about policy measures that can potentially enhance the security of flying car. Due to the emergent nature and lack of public exposure of this technology, individuals' perceptions and opinions regarding flying cars might be subject to several layers of unobserved heterogeneity, such as shared unobserved variations across interrelated perceptions, grouped effects, and interactive effects between various sources of unobserved heterogeneity. To explore individuals' perceptions accounting, at the same time, for such heterogeneity patterns, grouped random parameters bivariate probit and correlated grouped random parameters binary probit models with heterogeneity in means are estimated. In this context, data collected from an online survey of 584 individuals from the United States are statistically analyzed. The estimation results revealed that a number of individual-specific socio-demographic, behavioral and driving attributes affect the perceptions towards the safety aspects of flying cars, along with the attitudes towards potential security interventions. Despite the exploratory nature of the analysis, the findings of this study can provide manufacturers, policy-makers and regulating agencies with valuable information regarding the integration and acceptance challenges that may arise with the introduction of flying cars.

Keywords: Flying cars; Safety; Security; Correlated grouped random parameters; Bivariate probit models; Heterogeneity in means 


\section{INTRODUCTION}

Over the last decades, the constant demand for lower and reliable travel times, enhanced safety and security and ubiquitous access to various transportation modes has led to the deployment of new transportation technologies and systems. The latter typically aim to enhance the flexibility and sustainability of mobility patterns (such as the shared mobility systems - see also Schmöller et al., 2015; Bordagaray et al., 2016; Faghih-Imani et al., 2017), minimize the human error during the driving task (such as the autonomous vehicles -see also Fagnant and Kockelman, 2015; Lavieri et al., 2017; Talebian and Mishra, 2018), or both (such as the shared autonomous systems - see also Fagnant and Kockelman, 2016; Krueger et al., 2016; Menon et al., 2019). For all these technologies, the safety- or security-related implications constitute sources of implementation uncertainties that are commonly encountered by researchers, manufacturers and legislative entities (Bansal et al., 2016; Becker and Axhausen, 2017; Bansal and Kockelman, 2018; Xu and Fan, 2018; Sacks and Ortiz, 2018; Akyelken et al., 2018; Cui et al., 2018; De La Torre et al., 2018; Combs et al., 2019; Gkartzonikas and Gkritza. 2019).

One common characteristic of the above-mentioned transportation systems stems from their operational dependence on ground transportation networks. On the contrary, a newly emerging transportation mode, the flying car, has the potential to incorporate all the features of shared mobility and autonomous driving into a - spatially - dual operation: on the ground and in the air. Having semi- or fully-autonomous capabilities for vertical take-off and landing, the operation of flying cars will not significantly differ from conventional personal vehicles during the on-ground operation, and from personal jets during the in-air operation. With provisions for two to four passengers, flying cars are expected to accommodate trips on a distance up to 500 miles, requiring not more than 100 feet (in diameter) clearance zones at the trip origin and destination 
(see Eker et al., 2019a; Eker et al., 2019b; Ahmed et al., 2019). Recent developments and announcements have shown that flying cars are expected to be introduced in the automotive and aviation market between 2020 and 2025 (Becker, 2017; Oppitz and Tomsu, 2018). Over the last few years, various startups (to name a few, Terrafugia, AeroMobil, PAL-V, Opener and Kitty Hawk) and well-established automobile and aviation manufacturing companies (e.g. Airbus, Audi, Rolls Royce, Aston Martin) have demonstrated their flying car prototypes and revealed their plans to introduce flying cars in the near future (Muoio, 2017; Airbus, 2018; Opener, 2018; Rocco, 2018a; Rocco, 2018b; Rolls-Royce, 2018).

The currently available design concepts have shown that an abundance of safety features and assistance systems will be available during the flying car operation, such as a rigid safety cage, passenger airbags, rear-view cameras and a full vehicle parachute. Besides the technical features of flying cars, their operation in a dense urban environment may introduce challenges arising from their interactions with the built and physical environment. To address such challenges, NASA has started investigating, at a system-wide level, the implications of an integrated mobility framework that will unrestrictedly allow the air transportation of passengers and cargo within and across urban metropolitan areas. This framework, referred to as “Urban Air Mobility (UAM)” (see NASA, 2017 for more information), involves collaboration among the industry, academia and Federal Aviation Administration (FAA) on the generation of operational standards, safety regulations, and environmental impact assessments. To that end, various programs and initiatives are currently taking place across the globe, including simulations, conduct of test flights in a controlled environment and pilot deployment of air traffic management systems (Unmanned Airspace, 2018). In this context, NASA and Uber are currently collaborating to explore and evaluate technologies towards ensuring the smooth, safe and efficient operation of UAM, especially in dense urban 
settings. The identification of the most favorable operating conditions can, in turn, enable the development of industry standards, air traffic regulations and other legislative frameworks (NASA, 2018a; NASA, 2018b).

Considering the operational challenges of flying cars, especially in terms of safety and integration within the urban environment, the long-term establishment of flying cars is dependent on the public response to possible hazards that may be encountered by the users. Specifically, perceptions towards the safety implications (e.g. interactions with other vehicles; loss of connectivity, navigation or communication with the management systems) or possible security barriers (e.g., navigation tracking by non-authorized entities) typically have strong influence on the decision-making process of users (Bartolini et al., 2017; Hohenberger et al., 2017; Masoud and Jayakrishnan, 2017). Even though the development of operating regulations may attenuate possible public concerns to some extent, the complexities of the air mobility system may require a deep interchange between the regulating community and the potential users in order to enhance the public awareness and confidence on this new technology. In this context, the capturing of the current public awareness and perceptions towards the safety- or security-related barriers may serve as a baseline not only for producing user-oriented regulations, but also for expediting the societal integration of flying cars and urban air mobility systems.

In line with the aforementioned challenges, the goal of this study is to identify the key factors that affect the safety- and security-related public perceptions towards the operation of flying cars. In this context, public attitudes towards the effectiveness of possible preventive measures and policy interventions targeted on the security enhancement during a flying car trip are also explored. To that end, an online survey has been designed and distributed to individuals in order to gain opinions and perceptual attitudes related to flying cars' operations. Due to the 
absence of public exposure to the use of flying cars, the collected opinions might be affected by multiple layers of unobserved heterogeneity, rendering the subsequent statistical analysis a significant methodological challenge. To address the unobserved heterogeneity patterns underpinning the survey data, advanced bivariate and univariate modeling approaches are employed. To model conceptually interrelated perceptions in a joint modeling framework, grouped random parameters bivariate probit models are estimated. The latter can account for various econometric challenges such as unobserved heterogeneity across the survey responses, unbalanced panel effects and cross equation error term correlation. The bivariate probit framework is leveraged for modeling individuals' perceived concerns towards safety consequences of equipment failures and towards accidents on airway as well as concerns about security against hackers or terrorists and about personal information privacy. The same framework is employed to statistically model individuals' expectations towards the possible reduction of number and severity of crashes on the roadway after the introduction of flying cars. As far as the possible securityrelated measures are concerned, factors affecting individuals’ opinions towards several measures are identified through the estimation of correlated grouped random parameters binary probit models with heterogeneity in means. The latter modeling approach can account for unobserved heterogeneity across the survey responses, unbalanced panel effects and unobserved heterogeneity interactions that can affect either the dependence structures (e.g., correlated random parameters) or the distributional characteristics (e.g., variations in the means) of random parameters. The results of the analysis show that individuals’ perceptions towards safety and security implications of flying cars are affected by a number of socio-demographic and behavioral characteristics as well as by their attitudinal propensity with respect to the general adoption and use of flying cars. 


\section{DATA}

To identify individuals’ expectations and opinions regarding key characteristics of flying cars, a web-based survey was conducted in March 2017 ${ }^{1}$ Specifically, 34 graduate students and employees of the University at Buffalo, serving as survey-distributors, disseminated the survey to 584 individuals within the United States. The number of responses collected through each of the distributors varied between 2 to 33, subsequently creating unbalanced panels in the dataset.

To make the respondents more aware of the features and operational characteristics of flying cars, the survey questions were preceded by an information session; the latter included a concise description, multiple images, and video illustrations about the capabilities of flying cars on ground and in the air. The survey questionnaire was oriented towards obtaining individuals’ perceptions on various aspects of flying cars' adoption and operation as well as towards understanding individuals’ socio-demographic and behavioral background. Specifically, the first set of questions focused on individuals' willingness to pay for a flying car under multiple scenarios of acquaintance cost. Furthermore, patterns of individuals' willingness to use a flying car were also explored considering various scenarios of trip characteristics, such as trip purpose, trip distance, and temporal characteristics of the trip.

Another set of questions aimed at gaining information about the perceived benefits and concerns arising from the use of flying cars. Possible benefits, for which individuals’ perceptions were captured, include fewer crashes and less severe crashes on the roadway, along with various other trip-, traffic-, cost-, and environment-specific benefits that may emerge after the introduction of flying cars. To identify the successive levels of public response to various implications of flying

\footnotetext{
${ }^{1}$ The survey was conducted using the online platform "SurveyMonkey”.
} 
cars, all the expectation- or perception-related questions were formulated on the basis of a fourpoint Likert scale. Specifically, for the willingness-to-pay, willingness-to-use and benefit-related perceptions, the respondents assessed the likelihood of occurrence of each possible outcome as “very unlikely”, “somewhat unlikely”, “somewhat likely”, or “very likely”.

To capture individuals’ concerns regarding the implications of flying cars, several questions focused on perceptions about safety- or security-related potential issues. The latter include the safety consequences of equipment/system failure, accidents on the airway, security against hackers/terrorists and issues associated with personal information privacy (e.g., location/destination monitoring) after the emergence of flying cars in the traffic fleet. Following a similar rating scale with the questions from the previous section, the respondents' degree of concern was captured through a four-point Likert scale, with the possible options being "Not at all concerned”, “Slightly concerned”, “Moderately concerned”, and "Very concerned”. Similarly, respondents provided their attitudinal stances towards possible preventive measures and policy interventions that can address various security issues arising from the operation of flying cars. The proposed measures and interventions include the use of existing FAA regulations for air traffic control, establishment of air-road police enforcement (with flying police cars), detailed profiling and background checking of flying car owners/operators, and establishment of no-fly zones for flying cars near sensitive locations (military bases, power/energy plants, governmental buildings, major transportation hubs, etc.).

The subsequent set of questions aims at understanding individuals' familiarity with emerging vehicle technologies in terms of level 1 and level 2 automation features (e.g., emergency automatic braking, adaptive cruise control, blind spot monitoring, etc.). The underlying purpose of this set of questions is to serve as a surrogate measure to understand individuals' level of 
exposure to emerging vehicle technologies, which in turn, may impact their perception towards flying cars.

The last set of questions focused on individuals’ socio-economic and behavioral attributes. Specifically, the participants were questioned about their socio-economic background (e.g., marital status, educational status, income, gender, age, household characteristics), their driving past (e.g., driving experience and exposure, number and severity of accidents they were involved), as well as about their current behavioral patterns. The latter refer to broad spectrum of habitual activities, including, for example, alcohol consumption, driving habits when approaching a traffic signal, driving style and preferences, attitudes towards speed limits.

The collected sample consists of $58.5 \%$ of male respondents, compared to $49.2 \%$ in the U.S. nationally. The median age is 25 years compared to the national median of 37.8 years. In terms of educational attainment level, $74.38 \%$ of the respondents had a college degree or higher compared to $30.9 \%$ nationally. With regard to the household income level, $68.44 \%$ of the respondents are from households having annual income above $\$ 50,000$ compared to 56.2\% nationally. In addition, $10.44 \%$ of the respondents indicated that their current residences are located at city center areas, whereas 30.92\% indicated urban areas outside of city centers. On the contrary, $48.58 \%$ and $10.06 \%$ respondents indicated that their residences are located at suburban and rural areas, respectively. For additional studies conducted based on the aforementioned survey data, please see Ahmed et al., 2019 and Eker et al., (2019a, 2019b).

Table 1 presents the responses of individuals’ perceptions regarding the safety and security concerns of flying cars as well as regarding potential measures that may enhance the security of flying cars. The percentage corresponding to the "overall unlikely" outcome includes the individuals who selected the "very unlikely" or "somewhat unlikely" outcome. Similar 
aggregation was adopted for the "overall likely" outcome. Furthermore, the percentage corresponding to the "overall concerned" outcome includes the individuals who selected the “moderately concerned" or "very concerned" outcome, whereas the "overall unconcerned" outcome is derived from the aggregation of the "not at all concerned" and "slightly concerned" outcomes. Table 2 provides descriptive statistics of key variables that were found to be statistically significant determinants of individuals’ perceptions and opinions in the statistical analysis. Table 1 shows that the majority of respondents expect that the introduction of flying cars will result in fewer and less severe crashes on the roadway $(65.98 \%$ and $57.33 \%$ of the respondents, respectively). On the other hand, the vast majority of the respondents are overall concerned for the safety consequences of equipment/system failure and the possibility of accident occurrence on the airway (84.43\% and $82.18 \%$ of the respondents, respectively). Similarly, the majority of the respondents are overall concerned with the level of security against hackers/terrorists and the emergence of issues relating to personal information privacy (e.g., location/destination monitoring), as indicated by $69.98 \%$ and $66.98 \%$ of the respondents, respectively. Table 1 also shows that the respondents have highly favorable opinions towards various security measures. Specifically, the majority of the individuals believe that the use of FAA regulations for air traffic control, the establishment of air-road police enforcement, the detailed profiling and background checking of flying car owners/operators, and the establishment of no-fly zones near sensitive locations has the potential to increase the level of security against hackers/terrorists (61.02\%, 70.62\%, 75.23\%, and 79.03\% of the respondents, respectively). 
Table 1. Distribution of respondents' perceptions about safety- and security-related benefits and concerns as well as about the effectiveness of possible security measures.

\begin{tabular}{|c|c|c|c|c|c|c|}
\hline & $\begin{array}{c}\text { Very } \\
\text { unlikely }\end{array}$ & $\begin{array}{l}\text { Somewhat } \\
\text { unlikely }\end{array}$ & $\begin{array}{l}\text { Overall } \\
\text { unlikely }\end{array}$ & $\begin{array}{l}\text { Somewhat } \\
\text { likely }\end{array}$ & Very likely & $\begin{array}{l}\text { Overall } \\
\text { likely }\end{array}$ \\
\hline \multicolumn{7}{|l|}{ Safety Benefits } \\
\hline Fewer crashes on the roadway & $12.03 \%$ & $21.99 \%$ & $34.02 \%$ & $41.54 \%$ & $24.44 \%$ & $65.98 \%$ \\
\hline $\begin{array}{l}\text { Less severe crashes on the } \\
\text { roadway }\end{array}$ & $17.67 \%$ & $25.00 \%$ & $42.67 \%$ & $38.16 \%$ & $19.17 \%$ & $57.33 \%$ \\
\hline \multicolumn{7}{|l|}{ Security Measures } \\
\hline $\begin{array}{l}\text { Use existing FAA regulations for } \\
\text { air traffic control }\end{array}$ & $16.76 \%$ & $22.22 \%$ & $38.98 \%$ & $41.62 \%$ & $19.40 \%$ & $61.02 \%$ \\
\hline \\
\hline $\begin{array}{l}\text { enforcement (with flying police } \\
\text { cars) }\end{array}$ & $10.17 \%$ & $19.21 \%$ & $29.38 \%$ & $42.56 \%$ & $28.06 \%$ & $70.62 \%$ \\
\hline $\begin{array}{l}\text { Detailed profiling and } \\
\text { background checking of flying } \\
\text { car owners/operators }\end{array}$ & $9.57 \%$ & $15.20 \%$ & $24.77 \%$ & $39.59 \%$ & $35.65 \%$ & $75.23 \%$ \\
\hline \multicolumn{7}{|l|}{$\begin{array}{l}\text { Establish no-fly zones for flying } \\
\text { cars near sensitive locations } \\
\text { (military bases, power/energy } \\
\text { plants, governmental buildings, } \\
\text { major transportation hubs, etc.) }\end{array}$} \\
\hline & $\begin{array}{l}\text { Not at all } \\
\text { concerned }\end{array}$ & $\begin{array}{l}\text { Slightly } \\
\text { concerned }\end{array}$ & $\begin{array}{c}\text { Overall } \\
\text { unconcerned }\end{array}$ & $\begin{array}{l}\text { Moderately } \\
\text { concerned }\end{array}$ & $\begin{array}{c}\text { Very } \\
\text { concerned }\end{array}$ & $\begin{array}{c}\text { Overall } \\
\text { concerned }\end{array}$ \\
\hline \multicolumn{7}{|l|}{ Safety Concerns } \\
\hline $\begin{array}{l}\text { Safety consequences of } \\
\text { equipment/system failure }\end{array}$ & $4.13 \%$ & $11.44 \%$ & $15.57 \%$ & $25.14 \%$ & $59.29 \%$ & $84.43 \%$ \\
\hline Accidents on the airway & $4.32 \%$ & $13.51 \%$ & $17.82 \%$ & $25.89 \%$ & $56.29 \%$ & $82.18 \%$ \\
\hline \multicolumn{7}{|l|}{ Security Concerns } \\
\hline $\begin{array}{l}\text { Security } \\
\text { hackers/terrorists }\end{array}$ & $6.75 \%$ & $23.26 \%$ & $30.02 \%$ & $27.95 \%$ & $42.03 \%$ & $69.98 \%$ \\
\hline $\begin{array}{l}\text { Personal information privacy } \\
\text { (location/destination } \\
\text { monitoring) }\end{array}$ & $10.38 \%$ & $22.64 \%$ & $33.02 \%$ & $30.94 \%$ & $36.04 \%$ & $66.98 \%$ \\
\hline
\end{tabular}


Table 2. Descriptive statistics of key variables

\begin{tabular}{|c|c|c|c|c|}
\hline Variable description & Mean & $\begin{array}{l}\text { Std. } \\
\text { Dev. }\end{array}$ & Min. & Max. \\
\hline \multicolumn{5}{|l|}{ Socio-demographics } \\
\hline $\begin{array}{l}\text { Gender indicator ( } 1 \text { if the respondent is male, } 0 \\
\text { otherwise) }\end{array}$ & 0.585 & - & 0 & 1 \\
\hline Inverse of square of the age of the respondent & 0.002 & 0.001 & 0.0001 & 0.004 \\
\hline $\begin{array}{l}\text { Age indicator ( } 1 \text { if the respondent is younger than } 25 \text {, } \\
0 \text { otherwise) }\end{array}$ & 0.500 & - & 0 & 1 \\
\hline $\begin{array}{l}\text { Age indicator ( } 1 \text { if the respondent is younger than } 30 \text {, } \\
0 \text { otherwise) }\end{array}$ & 0.734 & - & 0 & 1 \\
\hline $\begin{array}{l}\text { Age indicator (1 if the respondent is older than } 50,0 \\
\text { otherwise) }\end{array}$ & 0.087 & - & 0 & 1 \\
\hline $\begin{array}{l}\text { Current living area indicator ( } 1 \text { if the respondent lives } \\
\text { in rural area, } 0 \text { otherwise) }\end{array}$ & 0.100 & - & 0 & 1 \\
\hline $\begin{array}{l}\text { Ethnicity indicator ( } 1 \text { if the respondent is Asian, } 0 \\
\text { otherwise) }\end{array}$ & 0.180 & - & 0 & 1 \\
\hline $\begin{array}{l}\text { Ethnicity indicator ( } 1 \text { if the respondent is Caucasian, } 0 \\
\text { otherwise) }\end{array}$ & 0.626 & - & 0 & 1 \\
\hline $\begin{array}{l}\text { Education indicator ( } 1 \text { if the respondent has a technical } \\
\text { college degree or a college degree, } 0 \text { otherwise) }\end{array}$ & 0.541 & - & 0 & 1 \\
\hline $\begin{array}{l}\text { Income indicator ( } 1 \text { if the respondent's annual } \\
\text { household income is less than } \$ 50,000,0 \text { otherwise) }\end{array}$ & 0.296 & - & 0 & 1 \\
\hline $\begin{array}{l}\text { Income indicator ( } 1 \text { if the respondent's annual } \\
\text { household income is less than } \$ 75,000,0 \text { otherwise) }\end{array}$ & 0.464 & - & 0 & 1 \\
\hline $\begin{array}{l}\text { Income indicator ( } 1 \text { if the respondent's annual } \\
\text { household income is between } \$ 50,000 \text { and } \$ 150,000 \text {, } \\
0 \text { otherwise) }\end{array}$ & 0.217 & - & 0 & 1 \\
\hline $\begin{array}{l}\text { Income indicator ( } 1 \text { if the respondent's annual } \\
\text { household income is greater than } \$ 100,000,0 \\
\text { otherwise) }\end{array}$ & 0.228 & - & 0 & 1 \\
\hline $\begin{array}{l}\text { No. of children indicator ( } 1 \text { if the respondent's } \\
\text { household has no child aged below } 6 \text { years, } 0 \\
\text { otherwise) }\end{array}$ & 0.931 & - & 0 & 1 \\
\hline \multicolumn{5}{|l|}{ Opinions and preferences } \\
\hline $\begin{array}{l}\text { Familiarity with vehicle safety features indicator ( } 1 \text { if } \\
\text { the respondent is not familiar with advanced safety } \\
\text { features, } 0 \text { otherwise) }\end{array}$ & 0.126 & - & 0 & 1 \\
\hline $\begin{array}{l}\text { Familiarity with vehicle safety features indicator ( } 1 \text { if } \\
\text { the respondent never owned a car with an advanced } \\
\text { safety feature, } 0 \text { otherwise) }\end{array}$ & 0.456 & - & 0 & 1 \\
\hline $\begin{array}{l}\text { Aggressive driving indicator ( } 1 \text { if the respondent } \\
\text { thinks that s/he normally drives not aggressively, } 0 \\
\text { otherwise) }\end{array}$ & 0.418 & - & 0 & 1 \\
\hline
\end{tabular}


Aggressive driving indicator (1 if the respondent thinks that s/he normally drives very aggressively, 0 otherwise)

Driving speed indicator (1 if the respondent normally drives faster than $65 \mathrm{mph}$ on an interstate with a 65 mph speed limit and little traffic, 0 otherwise)

Speed limit opinion indicator (1 if the respondent completely disagrees with the statement: "Speed limits on high speed freeways should only be suggestive", 0 otherwise)

Speed limit opinion indicator ( 1 if the respondent is neutral with the statement: "Speed limits on high speed freeways should only be suggestive", 0 otherwise)

Speed limit opinion indicator (1 if the respondent completely agrees with the statement: "Speed limits on high speed freeways should only be suggestive", 0 otherwise)

Speed limit opinion indicator (1 if the respondent disagrees or completely disagrees with the statement: "Speed limits on high speed freeways should only be suggestive", 0 otherwise)

Driver preference indicator (1 if the respondent generally prefers to drive herself/himself when there are more than two licensed drivers in a vehicle on a trip, 0 otherwise)

Driver preference indicator (1 if the respondent generally prefers to have the other driver drive when there are more than two licensed drivers in a vehicle on a trip, 0 otherwise)

Driver preference indicator (1 if the respondent is not sure about driving herself/himself when there are more than two licensed drivers in a vehicle on a trip, 0 otherwise)

Accident history indicator ( 1 if the respondent has had at least one non-severe or severe accident in the last 5 years, 0 otherwise)

Accident history indicator ( 1 if the respondent has had more than one non-severe accidents in the last 5 years, 0 otherwise)

Driving experience indicator ( 1 if the respondent has a driving license for over 15 years, 0 otherwise)

Annual mileage driven (in 1000 miles)

Mileage indicator ( 1 if the respondent annually drives less than 5,000 miles, 0 otherwise)

\begin{tabular}{|c|c|c|}
\hline 0.100 & - & 0 \\
\hline 0.816 & - & 0 \\
\hline 0.094 & - & 0 \\
\hline 0.383 & - & 0 \\
\hline 0.119 & - & 0 \\
\hline 0.299 & - & 0 \\
\hline 0.462 & - & 0 \\
\hline 0.244 & - & 0 \\
\hline 0.294 & - & 0 \\
\hline 0.325 & - & 0 \\
\hline 0.093 & - & 0 \\
\hline 0.208 & - & 0 \\
\hline 11.059 & 9.864 & 0 \\
\hline 0.264 & - & 0 \\
\hline
\end{tabular}


Mileage indicator (1 if the respondent annually drives more than 10,000 miles, 0 otherwise)

Mileage indicator ( 1 if the respondent annually drives more than 15,000 miles, 0 otherwise)

$0.417-0 \quad 1$

$0.194-0 \quad 0 \quad 1$ 


\section{METHODOLOGICAL APPROACH}

To shed more light on the factors affecting individuals' perceptions, the safety- and security-specific responses are statistically modeled. To that end, two major categories of discrete outcome approaches are employed: bivariate and univariate binary probit models.

\subsection{Grouped Random Parameters Bivariate Probit Framework}

From a methodological standpoint, the individuals' perceptions of the safety-related benefits or concerns may constitute major sources of systematic unobserved variations (Eker et al., 2019b). Such variations may be viewed as a result of common perceptual patterns across conceptually similar benefits or concerns. For example, individuals may similarly perceive the benefits associated with fewer crashes on the roadway and the benefits associated with less severe crashes on the roadway. Therefore, the presence of commonly shared unobserved variations across variables representing perceptions of - conceptually related - benefits or concerns may be highly likely. Such unobserved variations are typically captured by the error terms corresponding to the specific dependent variables. In case of interrelated dependent variables, there is a strong possibility for the error terms to be correlated (Sarwar et al., 2017a; Sarwar et al., 2017b; Pantangi et al., 2019; Fountas and Anastasopoulos, 2018). To account for this possibility, the bivariate modeling framework is employed. This framework allows for simultaneous modeling of two dependent variables that share similar or same unobserved characteristics, while accounting concurrently for the correlation of the relevant error terms (this type of correlation is typically referred to as contemporaneous or cross-equation error term correlation).

For the statistical analysis of safety- and security-related perceptions, the bivariate modeling framework is coupled with the binary logit approach. The latter is selected because the 
four ordinal responses of the survey - dependent variables were merged into two discrete outcomes for modeling purposes. Specifically, for the benefit-specific questions, the corresponding dependent variables have two discrete outcomes: “overall likely” and “overall unlikely”; similarly, the concern-specific dependent variables also have two discrete outcomes: "overall concerned" and “overall unconcerned”. Despite the possibility of introducing aggregation bias, the consideration of two discrete outcomes allows for conceptually close perceptual states to be captured by a homogeneous outcome. In this context, the bivariate probit model can be defined as (Sarwar et al., 2017a; Greene, 2016; Pantangi et al., 2019):

$$
\begin{aligned}
& W_{i, 1}=\boldsymbol{\beta}_{i, 1} \mathbf{X}_{i, 1}+\varepsilon_{i, 1}, \quad w_{i, 1}=1 \text { if } W_{i, 1}>0, \text { and } w_{i, 1}=0 \text { otherwise } \\
& W_{i, 2}=\boldsymbol{\beta}_{i, 2} \mathbf{X}_{i, 2}+\varepsilon_{i, 2}, \quad w_{i, 2}=1 \text { if } W_{i, 2}>0, \text { and } w_{i, 2}=0 \text { otherwise }
\end{aligned}
$$

with the error terms being expressed as:

$$
\left(\begin{array}{c}
\varepsilon_{i, 1} \\
\varepsilon_{i, 2}
\end{array}\right) \sim N\left[\left(\begin{array}{l}
0 \\
0
\end{array}\right),\left(\begin{array}{cc}
1 & \lambda \\
\lambda & 1
\end{array}\right)\right]
$$

where, $\mathbf{X}$ represents a vector of explanatory variables that determine individuals' safety- or security-related perceptions of flying cars, $\boldsymbol{\beta}$ denotes a vector of parameters with respect to $\mathbf{X}, w_{\mathrm{i}, 1}$ and $w_{\mathrm{i}, 2}$ represent the observed binary outcomes of the dependent variables, $\varepsilon$ is a random error term specified to follow the standard normal distribution, and $\lambda$ denotes the cross-equation correlation coefficient of the error terms. The cumulative function of the bivariate normal distribution as well as the corresponding log-likelihood function are formulated as (Greene, 2016),

$$
\Phi\left(W_{1}, W_{2}, \lambda\right)=\frac{\exp \left[-0.5\left(W_{1}^{2}+W_{2}^{2}-2 \rho W_{1} W_{2}\right) /\left(1-\lambda^{2}\right)\right]}{\left[2 \pi \sqrt{\left(1-\lambda^{2}\right)}\right]}
$$

and 


$$
\begin{aligned}
& \sum_{i=1}^{N}\left[w_{i, 1} w_{i, 2} \ln \Phi\left(\boldsymbol{\beta}_{i, 1} \mathbf{X}_{i, 1}, \boldsymbol{\beta}_{i, 2} \mathbf{X}_{i, 2}, \lambda\right)+\left(1-w_{i, 1}\right) w_{i, 2} \ln \Phi\left(-\boldsymbol{\beta}_{i, 1} \mathbf{X}_{i, 1}, \boldsymbol{\beta}_{i, 2} \mathbf{X}_{i, 2},-\lambda\right)\right. \\
& \left.+\left(1-w_{i, 2}\right) w_{i, 1} \ln \Phi\left(\boldsymbol{\beta}_{i, 1} \mathbf{X}_{i, 1},-\boldsymbol{\beta}_{i, 2} \mathbf{X}_{i, 2},-\lambda\right)+\left(1-w_{i, 1}\right)\left(1-w_{i, 2}\right) \ln \Phi\left(-\boldsymbol{\beta}_{i, 1} \mathbf{X}_{i, 1},-\boldsymbol{\beta}_{i, 2} \mathbf{X}_{i, 2}, \lambda\right)\right]
\end{aligned}
$$

Given the nature of the survey-based data collection, personal preferences and experience, limited awareness about new technologies, or other individual-specific behavioral patterns may not be captured introducing, thus, additional sources of underlying variations (Kang et al., 2013). To account for the effect of unobserved characteristics on the statistical analysis of the survey data (i.e., unobserved heterogeneity and its implications - see also Mannering and Bhat, 2014; Russo et al., 2014; Anastasopoulos, 2016; Mannering et al., 2016; Anastasopoulos et al., 2017; Fountas, 2018; Mannering, 2018; Barbour et al., 2019; Sheela and Mannering, 2019), random parameters are introduced in the bivariate probit framework. The random parameters allow for the parameter estimates to vary across the observational units according to a pre-specified distribution. Even though the individual survey responses constitute the most disaggregate observational unit, the survey responses corresponding to the same survey distributor may share similar, yet systematic variations implying, thus, the possible presence of unbalanced panel effects. To account for the latter, the parameters are specified to vary, not across the individual survey responses, but across groups of distributor-specific responses, leading, as such, to the estimation of grouped random parameters (Sarwar et al., 2017a; Sarwar et al., 2017c; Fountas et al., 2018a; Fountas et al., 2018c; Cai et al., 2018; Heydari et al., 2018; Pantangi et al., 2019). Specifically, the grouped random parameters are formulated as (Fountas and Anastasopoulos, 2017; Sarwar et al., 2017a; Anastasopoulos et al. 2017; Fountas et al., 2018b, 2018c; Menon et al., 2019):

$$
\boldsymbol{\beta}_{k}=\boldsymbol{\beta}+v_{k}
$$


where, $\boldsymbol{\beta}$ denotes the vector of parameters and $v_{k}$ denotes a random, distributor-specific term with zero mean and variance $\sigma^{2}$. As far as the distributional characteristics of the grouped random parameters are concerned, several common distributions (e.g., normal, log-normal, triangular, uniform, and Weibull) were explored; the normal distribution was found to provide the best statistical fit and, thus, was employed for model estimation.

Due to the computationally demanding numerical integrations required for the estimation of the grouped random parameters within a bivariate probit context, a simulated likelihood estimation approach is employed. With this approach, the numerical approximations for the parameter estimation are produced by an iterative process, which is based on Halton sequences (Halton, 1960). It should be noted that 500 Halton draws were found to offer parameter stability in model estimation (Anastasopoulos, 2016; Amoh-Gyimah et al., 2017; Fountas et al., 2018c).

In addition, to identify the magnitude of the effect of independent variables on individuals’ perceptions, (pseudo-) elasticities are also estimated. The elasticities quantify the effect of $1 \%$ change of any continuous independent variable on the probability relating to the dependent variable, with their computation being defined as (Washington et al., 2011):

$$
E=\left[1-\Phi\left(\frac{\beta_{k} X_{k, i}}{\sigma}\right)\right] \beta_{k} X_{k, i}
$$

To identify the effect on individuals’ perceptions, due to a change of any indicator variable from “ 0 ” to “ 1 ”, the pseudo-elasticity is computed as (Washington et al., 2011):

$$
E=\Phi\left(\frac{\beta_{j} X_{j, 1}}{\sigma} \mid X_{i}=1\right)-\Phi\left(\frac{\beta_{j} X_{j, 1}}{\sigma} \mid X_{i}=0\right)
$$




\subsection{Correlated Grouped Random Parameters Probit Model with Heterogeneity in Means}

In the context of a binary probit model formulation, the traditional probability model is defined as (Greene, 2017),

$$
\mathrm{Y}_{\mathrm{i}}=\boldsymbol{\beta}_{\mathrm{i}} \mathbf{X}_{\mathrm{i}}+\varepsilon_{\mathrm{i}}, \quad \mathrm{y}_{\mathrm{i}}=1 \text { if } \mathrm{Y}_{\mathrm{i}}>0 \text {, and } \mathrm{y}_{\mathrm{i}}=0 \text { otherwise }
$$

where, $\mathbf{X}$ is a vector of explanatory variables that affect respondents' opinions on potential measures to increase the security of flying car, $\boldsymbol{\beta}$ represents a vector of estimable parameters corresponding to $\mathbf{X}, y$ corresponds to integer binary outcome (zero or one), and $\varepsilon$ is a normally distributed random error term (with mean equal to zero and variance equal to one).

Similar to the bivariate probit model, to account for the effect of unobserved factors that can vary systematically across the responses, random parameters are estimated. The generalized formulation of the random parameters can be defined as (Greene, 2017),

$$
\boldsymbol{\beta}_{\mathrm{i}}=\boldsymbol{\beta}+\Theta \mathrm{Z}_{\mathrm{i}}+\Gamma \delta_{\mathrm{i}}
$$

where $\boldsymbol{\beta}$ denotes the mean value of the random parameters vector, i denotes the observational unit of the analysis, $\mathbf{Z}_{\mathrm{i}}$ is a vector of explanatory variables that influence the mean of $\boldsymbol{\beta}_{\mathbf{i}}$ (Venkataraman et al., 2014; Seraneeprakarn et al., 2017; Xin et al., 2017), $\Theta$ is a vector of estimable parameters that determine the mean of the random parameter distribution (Behnood and Mannering, 2017a; Behnood and Mannering, 2017b), $\Gamma$ is the Cholesky matrix whose elements are used for the computation of standard deviations of the random parameters, and $\delta$ denotes a randomly distributed term with mean equal to zero and variance equal to one. According to the generalized formulation of random parameters provided in Equation 9, the mean of the random parameter distribution is not treated as a constant value, but it can vary as a function of unique explanatory 
variables. The latter is particularly important, since it may capture possible heterogeneity effects that impose direct variations on the distributional characteristics of random parameters (i.e. heterogeneity in the means of random parameters), leading, in turn, to indirect variations in the effect of $\boldsymbol{\beta}$ s across the observations (Behnood and Mannering, 2017a; Behnood and Mannering, 2017b).

To account for possible correlations between the random parameters, an unrestrictive version of the $\Gamma$ matrix is employed, in which the off-diagonal elements are specified as non-zero values (unlike with the conventional random parameters approach). These non-zero off-diagonal elements may indirectly capture possible correlation effects between the unobserved characteristics, which can subsequently introduce possible inter-dependencies between the random parameters (Greene, 2012, Fountas et al., 2018b; Fountas et al., 2018c). Such inter-dependencies can be identified through the estimation of correlated random parameters (Mannering et al., 2016; Fountas et al., 2018b; Fountas et al., 2018c; Balusu et al., 2018). To concurrently account for grouped effects across the distributor-specific responses as well as for unobserved heterogeneity correlation between the explanatory variables, the employed form of the $\Gamma$ matrix enables the estimation of correlated grouped random parameters. Under such modeling consideration, a separate coefficient ( $\boldsymbol{\beta})$ is estimated for each distributor-specific group of survey responses. Therefore, all the survey responses associated with the same distributor are represented by a single random parameter coefficient (Sarwar et al., 2017a).

The standard deviations of the correlated random parameters are computed using the diagonal and off-diagonal elements of the $\Gamma$ matrix, as:

$$
\sigma_{j}=\sqrt{{\sigma_{k, k}^{2}+{\sigma_{k, k-1}}^{2}+{\sigma_{k, k-2}}^{2}+\ldots+\sigma_{k, 1}^{2}}^{2}}
$$


where, $\sigma_{j}$ denotes the standard deviation of the specific random parameter $j, \sigma_{k, k}$ is the respective diagonal element of the $\Gamma$ matrix and $\sigma_{k, k-1}, \sigma_{k, k-2} \ldots \sigma_{k, 1}$ denote the below diagonal elements of the estimated $\Gamma$ matrix. The standard error and $t$-statistic corresponding to the standard deviation of each random parameter are computed by applying the following procedure (see Fountas et al., 2018c, for further details). The standard error can be computed as:

$$
S E_{\sigma_{j}}=\frac{S_{\sigma_{\text {jn }}}}{\sqrt{N}}
$$

where, $S E_{\sigma_{j}}$ is the standard error of the standard deviation (averaged across all observations), $S_{\sigma_{j n}}$ is the standard deviation of the observation-specific $\sigma_{j n}$ and $N$ is the number of observations, which is the number of groups of distributor-specific responses, in this case. Then, the $t$-statistic is computed as,

$$
t_{\sigma j}=\frac{\sigma_{j}}{S E_{\sigma_{j}}}
$$

To gain deeper insights into the magnitude of the effect of each independent variable of the binary probit model, pseudo-elasticities are estimated. In this study, pseudo-elasticities measure the effect of a unit change of a specific variable on the probability of an individual to select the "overall likely" outcome regarding the effectiveness of various security measures. Since the vast majority of explanatory variables are indicator variables, the pseudo-elasticities will provide the effect on the dependent variable, due to a shift of the value of an independent variable from zero to one. 


\section{ANALYSIS RESULTS}

To identify the determinants of individuals' perceptions towards the future use of flying cars, grouped random parameters bivariate probit models are estimated for pairs of safety- and security-related survey responses. The selection of the dependent variables of the bivariate models is based on two criteria: (i) the possibility of conceptually interrelated safety- and security-specific perceptions; and (ii) the identification of statistically significant error term correlation between the dependent variables representing the aforementioned perceptions. ${ }^{2}$ Furthermore, to investigate the individuals' opinions about the effectiveness of several security measures, correlated grouped random parameters probit models with heterogeneity in means were developed. For model estimation, all possible variables and variable combinations were examined. Variables that were identified as statistically significant at 0.90 level of confidence or higher, are included in the model specifications. However, in cases where the mean of a random parameter was found to be statistically insignificant with the standard deviation being statistically significant, a chi-square distributed likelihood ratio test with two degrees of freedom (representing the mean and standard deviation of the random parameter's density function) was conducted to evaluate the improvement in overall statistical fit of the model (Washington et al., 2011). If the improvement was found to be statistically significant, the random parameters under consideration were included in the final model specifications. For the grouped random parameters bivariate probit models, the statistical significance and the magnitude of the cross-equation correlation coefficients further substantiate the use of the bivariate modeling framework. With regard to the models estimated within the binary

\footnotetext{
${ }^{2}$ Note that multivariate probit models were initially estimated in order to statistically investigate the cross-equation correlation of the error terms corresponding to the potential dependent variables of the bivariate models. The results of the multivariate probit models showed that pairs of variables with significant conceptual similarity (e.g., variables reflecting safety benefits or security concern perceptions) lead to statistically significant and strong - in magnitude cross-equation error term correlation. Therefore, these pairs of variables were used as dependent variables in the grouped random parameters bivariate probit models.
} 
probit framework, all possible variable combinations were also examined to concurrently achieve the best statistical fit and identify statistically significant random parameters correlation, as well as heterogeneity in the means of the random parameters. In cases when the best statistical fit didn’t result in correlated random parameters or statistically significant heterogeneity in means, the model specifications are presented as is.

4.1. Perceptions on safety-related benefits and concerns arising from the use of flying cars Tables 3 and 4 present the estimation results and (pseudo-)elasticities of the bivariate model of individuals' expectations about the potential of flying cars to result in fewer and less severe crashes on the roadway, respectively. The estimation results and (pseudo-)elasticities of the bivariate model of individuals’ concerns about the safety consequences of equipment/system failure and accidents on the airway from the future use of flying cars are presented in Tables 5 and 6 , respectively. 
Table 3. Estimation results of the grouped random parameters bivariate probit model of crashrelated perceptions

\begin{tabular}{|c|c|c|c|c|}
\hline \multirow[t]{2}{*}{ Variable } & \multicolumn{2}{|c|}{$\begin{array}{l}\text { Fewer crashes on } \\
\text { the roadway }\end{array}$} & \multicolumn{2}{|c|}{$\begin{array}{l}\text { Less severe } \\
\text { crashes on the } \\
\text { roadway }\end{array}$} \\
\hline & Coeff. & $t$-stat & Coeff. & t-stat \\
\hline \multicolumn{5}{|l|}{ Socio-demographics } \\
\hline Gender indicator ( 1 if the respondent is male, 0 otherwise) & 0.165 & 2.04 & - & - \\
\hline $\begin{array}{l}\text { Ethnicity indicator ( } 1 \text { if the respondent is Asian, } 0 \\
\text { otherwise) }\end{array}$ & 0.533 & 2.82 & 0.523 & 2.58 \\
\hline $\begin{array}{l}\text { Education indicator ( } 1 \text { if the respondent has a technical } \\
\text { college degree or a college degree, } 0 \text { otherwise) }\end{array}$ & - & - & -0.098 & -1.07 \\
\hline Standard deviation of parameter distribution & - & - & 0.313 & 4.38 \\
\hline $\begin{array}{l}\text { Income indicator ( } 1 \text { if the respondent's annual household } \\
\text { income is less than } \$ 50,000,0 \text { otherwise) }\end{array}$ & - & - & -0.191 & -1.44 \\
\hline Standard deviation of parameter distribution & - & - & 0.436 & 2.98 \\
\hline \multicolumn{5}{|l|}{ Opinions and Preferences } \\
\hline $\begin{array}{l}\text { Familiarity with vehicle safety features indicator ( } 1 \text { if the } \\
\text { respondent never owned a car with an advanced safety } \\
\text { feature, } 0 \text { otherwise) }\end{array}$ & - & - & -0.226 & -2.70 \\
\hline $\begin{array}{l}\text { Driver preference indicator ( } 1 \text { if the respondent is not sure } \\
\text { about driving herself/himself when there are more than } \\
\text { two licensed drivers in a vehicle on a trip, } 0 \text { otherwise) }\end{array}$ & 0.027 & 0.22 & - & - \\
\hline Standard deviation of parameter distribution & 0.424 & 3.63 & - & - \\
\hline $\begin{array}{l}\text { Mileage indicator ( } 1 \text { if the respondent annually drives less } \\
\text { than 5,000 miles, } 0 \text { otherwise) }\end{array}$ & 0.558 & 4.03 & 0.550 & 3.15 \\
\hline $\begin{array}{l}\text { Mileage indicator ( } 1 \text { if the respondent annually drives } \\
\text { more than } 15,000 \text { miles, } 0 \text { otherwise) }\end{array}$ & 0.417 & 2.65 & 0.516 & 3.31 \\
\hline Cross equation correlation (t-stat in parentheses) & \multicolumn{4}{|c|}{$0.965(57.75)$} \\
\hline Number of survey distributors & \multicolumn{4}{|c|}{34} \\
\hline Number of respondents & \multicolumn{4}{|c|}{456} \\
\hline Log-likelihood at convergence & \multicolumn{4}{|c|}{-447.78} \\
\hline Log-likelihood at zero & \multicolumn{4}{|c|}{-709.94} \\
\hline Akaike information criterion (AIC) & \multicolumn{4}{|c|}{925.60} \\
\hline
\end{tabular}

Aggregate distributional effect of random parameters across the respondents

\begin{tabular}{lcc}
\hline & Above zero & Below zero \\
\hline $\begin{array}{c}\text { Education indicator (1 if the respondent has a technical } \\
\text { college degree or a college degree, 0 otherwise) }\end{array}$ & $37.71 \%$ & $62.29 \%$ \\
$\begin{array}{l}\text { Income indicator (1 if the respondent's annual household } \\
\text { income is less than \$50,000, 0 otherwise) }\end{array}$ & $33.07 \%$ & $66.93 \%$ \\
$\begin{array}{l}\text { Driver preference indicator (1 if the respondent is not sure } \\
\text { about driving herself/himself when there are more than } \\
\text { two licensed drivers in a vehicle on a trip, 0 otherwise) }\end{array}$ & $52.54 \%$ & $47.46 \%$ \\
\hline
\end{tabular}


Table 4. (Pseudo-)elasticities of the explanatory variables included in the model of crash -related perceptions.

\begin{tabular}{|c|c|c|}
\hline Variable & $\begin{array}{c}\text { Fewer } \\
\text { crashes on } \\
\text { the } \\
\text { roadway } \\
\end{array}$ & $\begin{array}{c}\text { Less severe } \\
\text { crashes on } \\
\text { the } \\
\text { roadway } \\
\end{array}$ \\
\hline \multicolumn{3}{|l|}{ Socio-demographics } \\
\hline Gender indicator ( 1 if the respondent is male, 0 otherwise) & 0.065 & - \\
\hline Ethnicity indicator ( 1 if the respondent is Asian, 0 otherwise) & 0.157 & 0.163 \\
\hline $\begin{array}{l}\text { Education indicator ( } 1 \text { if the respondent has a technical college } \\
\text { degree or a college degree, } 0 \text { otherwise) }\end{array}$ & - & -0.010 \\
\hline $\begin{array}{l}\text { Income indicator ( } 1 \text { if the respondent's annual household income } \\
\text { is less than } \$ 50,000,0 \text { otherwise) }\end{array}$ & - & -0.052 \\
\hline \multicolumn{3}{|l|}{ Opinions and Preferences } \\
\hline $\begin{array}{l}\text { Familiarity with vehicle safety features indicator ( } 1 \text { if the } \\
\text { respondent never owned a car with an advanced safety feature, } \\
0 \text { otherwise) }\end{array}$ & - & -0.091 \\
\hline $\begin{array}{l}\text { Driver preference indicator ( } 1 \text { if the respondent is not sure about } \\
\text { driving herself/himself when there are more than two licensed } \\
\text { drivers in a vehicle on a trip, } 0 \text { otherwise) }\end{array}$ & 0.034 & - \\
\hline $\begin{array}{l}\text { Mileage indicator ( } 1 \text { if the respondent annually drives less than } \\
5,000 \text { miles, } 0 \text { otherwise) }\end{array}$ & 0.179 & 0.186 \\
\hline $\begin{array}{l}\text { Mileage indicator ( } 1 \text { if the respondent annually drives more than } \\
15,000 \text { miles, } 0 \text { otherwise) }\end{array}$ & 0.117 & 0.177 \\
\hline
\end{tabular}


Table 5. Estimation results of the grouped random parameters bivariate probit model of individuals' concerns regarding the safety consequences of equipment/system failure and accidents on the airway

\begin{tabular}{|c|c|c|c|c|}
\hline \multirow[t]{2}{*}{ Variable } & \multicolumn{2}{|c|}{$\begin{array}{c}\text { Safety } \\
\text { consequences of } \\
\text { equipment/system } \\
\text { failure }\end{array}$} & \multicolumn{2}{|c|}{$\begin{array}{l}\text { Accidents on the } \\
\text { airway }\end{array}$} \\
\hline & Coeff. & $t$-stat & Coeff. & t-stat \\
\hline Constant & 0.896 & 3.88 & 1.092 & 8.30 \\
\hline \multicolumn{5}{|l|}{ Socio-demographics } \\
\hline Inverse of square of the age of the respondent & -154.723 & -1.78 & - & - \\
\hline $\begin{array}{l}\text { Current living area indicator ( } 1 \text { if the respondent lives in rural } \\
\text { area, } 0 \text { otherwise) }\end{array}$ & - & - & 0.051 & 0.23 \\
\hline Standard deviation of parameter distribution & - & - & 0.901 & 3.35 \\
\hline $\begin{array}{l}\text { Income indicator ( } 1 \text { if the respondent's annual household } \\
\text { income is less than } \$ 50,000,0 \text { otherwise) }\end{array}$ & - & - & 0.296 & 1.06 \\
\hline Standard deviation of parameter distribution & - & - & 0.707 & 2.86 \\
\hline $\begin{array}{l}\text { Income indicator ( } 1 \text { if the respondent's annual household } \\
\text { income is between } \$ 50,000 \text { and } \$ 150,000 \text {, } 0 \text { otherwise) }\end{array}$ & 0.415 & 3.22 & - & - \\
\hline \multicolumn{5}{|l|}{ Opinions and Preferences } \\
\hline $\begin{array}{l}\text { Familiarity with vehicle safety features indicator ( } 1 \text { if the } \\
\text { respondent never owned a car with an advanced safety } \\
\text { feature, } 0 \text { otherwise) }\end{array}$ & 0.051 & 0.35 & - & - \\
\hline Standard deviation of parameter distribution & 0.230 & 2.77 & - & - \\
\hline $\begin{array}{l}\text { Aggressive driving indicator ( } 1 \text { if the respondent thinks that } \\
\text { s/he normally drives very aggressively, } 0 \text { otherwise) }\end{array}$ & - & - & 0.216 & 1.13 \\
\hline Standard deviation of parameter distribution & - & - & 0.532 & 3.03 \\
\hline $\begin{array}{l}\text { Driving speed indicator ( } 1 \text { if the respondent normally drives } \\
\text { faster than } 65 \mathrm{mph} \text { on an interstate with a } 65 \mathrm{mph} \text { speed } \\
\text { limit and little traffic, } 0 \text { otherwise) }\end{array}$ & 0.230 & 1.33 & - & - \\
\hline Standard deviation of parameter distribution & 0.128 & 2.18 & - & - \\
\hline $\begin{array}{l}\text { Speed limit opinion indicator ( } 1 \text { if the respondent completely } \\
\text { disagrees with the statement: "Speed limits on high speed } \\
\text { freeways should only be suggestive", } 0 \text { otherwise) }\end{array}$ & - & - & -0.407 & -1.73 \\
\hline $\begin{array}{l}\text { Driver preference indicator ( } 1 \text { if the respondent generally } \\
\text { prefers to drive herself/himself when there are more than } \\
\text { two licensed drivers in a vehicle on a trip, } 0 \text { otherwise) }\end{array}$ & - & - & -0.328 & -2.91 \\
\hline Cross equation correlation (t-stat in parentheses) & \multicolumn{4}{|c|}{$0.971(45.91)$} \\
\hline Number of survey distributors & \multicolumn{4}{|c|}{34} \\
\hline Number of respondents & \multicolumn{4}{|c|}{472} \\
\hline Log-likelihood at convergence & \multicolumn{4}{|c|}{-327.64} \\
\hline Log-likelihood at zero & \multicolumn{4}{|c|}{-490.47} \\
\hline Akaike information criterion (AIC) & \multicolumn{4}{|c|}{689.3} \\
\hline
\end{tabular}




\begin{tabular}{|c|c|c|}
\hline \multicolumn{3}{|c|}{ Aggregate distributional effect of random parameters across the respondents } \\
\hline & Above zero & $\overline{\text { Below zero }}$ \\
\hline $\begin{array}{l}\text { Current living area indicator ( } 1 \text { if the respondent lives in rural } \\
\text { area, } 0 \text { otherwise) }\end{array}$ & $52.26 \%$ & $47.74 \%$ \\
\hline $\begin{array}{l}\text { Income indicator ( } 1 \text { if the respondent's annual household } \\
\text { income is less than } \$ 50,000,0 \text { otherwise) }\end{array}$ & $66.23 \%$ & $33.77 \%$ \\
\hline $\begin{array}{l}\text { Familiarity with vehicle safety features indicator ( } 1 \text { if the } \\
\text { respondent never owned a car with an advanced safety } \\
\text { feature, } 0 \text { otherwise) }\end{array}$ & $58.77 \%$ & $41.23 \%$ \\
\hline $\begin{array}{l}\text { Aggressive driving indicator ( } 1 \text { if the respondent thinks that } \\
\text { s/he normally drives very aggressively, } 0 \text { otherwise) }\end{array}$ & $65.76 \%$ & $34.24 \%$ \\
\hline $\begin{array}{l}\text { Driving speed indicator ( } 1 \text { if the respondent normally drives } \\
\text { faster than } 65 \mathrm{mph} \text { on an interstate with a } 65 \mathrm{mph} \text { speed } \\
\text { limit and little traffic, } 0 \text { otherwise) }\end{array}$ & $96.38 \%$ & $3.62 \%$ \\
\hline
\end{tabular}


Table 6. (Pseudo-)elasticities of the explanatory variables included in the model of individuals' concerns regarding the safety consequences of equipment/system failure and accidents on the airway

Variable

Safety
consequences of
equipment/system
failure

\section{Socio-demographics}

Inverse of square of the age of the respondent $-0.001$

Current living area indicator ( 1 if the respondent lives in rural area, 0 otherwise)

Income indicator ( 1 if the respondent's annual household income is less than $\$ 50,000$, 0 otherwise)

Income indicator ( 1 if the respondent's annual household income is between $\$ 50,000$ and $\$ 150,000,0$ otherwise)

$\begin{array}{cc}-0.001 & 0.004 \\ - & 0.044 \\ 0.086 & - \\ -0.001 & - \\ - & 0.001 \\ 0.016 & -0.139 \\ - & -0.076 \\ - & \\ & \end{array}$

Opinions and Preferences

Familiarity with vehicle safety features indicator (1 if the respondent never owned a car with an advanced safety feature, 0 otherwise)

Aggressive driving indicator (1 if the respondent thinks that s/he normally drives very aggressively, 0 otherwise)

Driving speed indicator ( 1 if the respondent normally drives faster than $65 \mathrm{mph}$ on an interstate with a $65 \mathrm{mph}$ speed limit and little traffic, 0 otherwise)

Speed limit opinion indicator (1 if the respondent completely disagrees with the statement: "Speed limits on high speed freeways should only be suggestive”, 0 otherwise)

Driver preference indicator ( 1 if the respondent generally prefers to drive herself/himself when there are more than two licensed drivers in a vehicle on a trip, 0 otherwise) 
A number of socio-demographic characteristics are found to affect individuals’ perceptions regarding the safety benefits and concerns that may arise with the introduction of flying cars. For example, male respondents are more likely (by 0.065, as shown by its pseudo-elasticity in Table 4) to expect a decrease in the number of crashes on the roadway with the introduction of flying cars. Similarly, Asian respondents are more likely (by 0.157 and 0.163 , respectively) to expect an improvement in the number and severity of accidents on the roadway after the future introduction of flying cars. As far as the respondents' age is concerned, older people tend to be more concerned about the safety consequences of equipment/system failure. This finding demonstrates the perceptions of elderly travelers, who are either not well aware of the features of emerging transportation technologies, or are considerably biased against the technical uncertainties relating to the future operation of flying cars. The majority (62.29\%, as shown in Table 3) of respondents with a technical college or college degree does not acknowledge the potential of flying cars to result in less severe crashes on the roadway; whereas, about one third (37.71\%) of respondents with a technical college or college degree expect less severe crashes on the roadways. The living area of the respondents has a mixed effect on their opinion about possible safety benefits. Specifically, 52.26\% of the respondents (as shown in Table 5) who live in rural areas are more concerned about the accidents on the airway; whereas, $47.74 \%$ of the same category of respondents are less concerned about it. This finding may capture the air traffic-related perceptions of the individuals who live in rural areas. The likely lower exposure of such individuals in intensive air traffic patterns, which may involve interactions with the built environment in the case of flying cars, may render them less concerned about the mid-air collision that can result from the emergence of flying car. The income level of individuals' households is another statistically significant determinant, as shown in Table 3. In particular, 33.07\% of individuals from lower income 
households are more likely to anticipate less severe crashes on the roadway, whereas the remaining $66.93 \%$ of the respondents are less likely to expect such a safety benefit. Similarly, the majority of the respondents (66.23\%, as indicated in Table 5) from lower income households are more concerned about the possibility of accidents on the airway. Interestingly, individuals from medium to high income households are more likely (by 0.086, as shown in Table 6) to be concerned about equipment failure. These findings can be useful for manufacturing companies to develop training, simulation and testing programs and, as such, disseminate the technical details and potential benefits of flying cars to an appropriately targeted audience.

As far as the familiarity with advanced transportation technologies is concerned, individuals who never owned a car with advanced safety features have mixed concerns regarding the safety features of the flying cars. The consequences of equipment/system failure are found to be a more likely concern for the majority (58.77\%, as shown in Table 5) of these respondents; whereas, for the rest of the respondents ( $41.23 \%$, as shown in Table 5), the equipment failure is a less likely concern. This finding shows that the familiarity with the advanced technologies constitutes an influential factor of public perceptions, with less familiar individuals being intuitively more concerned about the safety implications of flying cars.

Moving to the behavioral and attitudinal determinants, $65.76 \%$ of the individuals (as indicated in Table 5) who perceive themselves as very aggressive drivers are more concerned about accidents on the airway with the future use of flying cars. Concerns about safety consequences of equipment/system failure slightly vary across drivers with self-reported speeding behavior (e.g., drivers who normally drive faster than $65 \mathrm{mph}$ on an interstate with speed limit of $65 \mathrm{mph}$ and little traffic). For the vast majority (96.38\%, as shown in Table 5) of these respondents, the selfreported speeding behavior increases the likelihood of concerns about safety consequences. On 
the contrary, individuals who completely disagree with the concept of having freeway speed limit as a suggestive measure are less likely (by -0.139 , as shown in Table 6) to be concerned about accidents on the airway. As expected, the self-consciousness of these respondents in conjunction with the prevailing uncertainty regarding the operating conditions of flying cars (e.g., pilot-assisted operation versus fully autonomous operation) may be leading to more reserved perceptions of the safety implications of flying cars.

Another source of perceptual variations arises from individuals with varying willingness to drive in shared trips (e.g., drivers who are not sure about driving themselves when other licensed drivers are also present in a vehicle). The majority (52.54\%, as shown in Table 3 ) of these individuals are more likely to expect fewer crashes with the use of flying cars, while the opposite is observed for the remaining $47.46 \%$. On the other hand, the respondents who prefer to drive themselves, when there are more than two licensed drivers in a vehicle, are less likely (by -0.076 , as shown by its pseudo-elasticity in Table 6) to consider the possibility of accidents on the airway as a concerning factor. Higher driving confidence may downgrade concerns about possible conflicts on the airway, since either the manual or autonomous operation of flying cars may be perceived as risk-free by the specific group of individuals.

Driving exposure has also influential effect in shaping individuals' opinions about the safety benefits and concerns of flying cars. Specifically, individuals with greater annual mileage (more than 15,000 miles per year) are more likely (by 0.117 and 0.177 , respectively, as shown by the elasticities in Table 4) to expect fewer and less severe crashes on the roadway after the future introduction of flying cars. Similarly, individuals with low annual mileage (less than 5,000 miles per year) are more likely to expect fewer and less severe crashes on the roadway (by 0.179 and 0.186, respectively). Both findings possibly capture the effect of habitual driving patterns on 
individuals' perceptions, since the experience of frequent car-users may lead to greater awareness and acknowledgment of the safety features of the emerging transportation technologies. Car-users with limited driving experience may similarly perceive the safety benefits of flying cars, especially those who extensively use new transportation systems for commuting, such as millennials (Polzin et al., 2014; Garikapati et al., 2016).

\subsection{Perceptions and opinions on security-related concerns and measures}

Tables 7 and 8 present the estimation results and (pseudo-)elasticities, respectively, of the bivariate model of individuals’ concerns about security against hackers/terrorists and personal information privacy (location/destination monitoring) with the use of flying cars. The estimation results and (pseudo-) elasticities of the binary probit model of individuals' opinions on the use of existing FAA regulations for air traffic control are presented in Tables 9 and 10, respectively. Tables 11 and 12 present the estimation results and (pseudo-) elasticities, respectively, of the binary probit model of individuals’ perceptions towards the effectiveness of establishing air-road police enforcement (with flying police cars). Tables 13 and 14 present the estimation results and (pseudo-) elasticities, respectively, of the binary probit model of individuals’ perceptions towards the detailed profiling and background checking of flying car owners/operators. Finally, the estimation results and elasticities of the binary probit model of individuals' opinions on establishing no-fly zones for flying cars near sensitive locations (military bases, power/energy plants, governmental buildings, major transportation hubs, etc.) are presented in Tables 15 and 16, respectively. 
Table 7. Estimation results of the grouped random parameters bivariate probit model of individuals' concerns regarding security against hackers/terrorists and personal information privacy (Location/destination monitoring)

\begin{tabular}{|c|c|c|c|c|}
\hline \multirow[t]{2}{*}{ Variable } & \multicolumn{2}{|c|}{$\begin{array}{c}\text { Security against } \\
\text { hackers/terrorists }\end{array}$} & \multicolumn{2}{|c|}{$\begin{array}{l}\text { Personal information } \\
\text { privacy } \\
\text { (Location/destination } \\
\text { monitoring) }\end{array}$} \\
\hline & Coeff. & $t$-stat & Coeff. & $t$-stat \\
\hline Constant & - & - & 0.687 & 4.37 \\
\hline \multicolumn{5}{|l|}{ Socio-demographics } \\
\hline $\begin{array}{l}\text { Age indicator (1 if the respondent is younger than } 25,0 \\
\text { otherwise) }\end{array}$ & 0.270 & 2.51 & - & - \\
\hline $\begin{array}{l}\text { Gender indicator ( } 1 \text { if the respondent is male, } 0 \\
\text { otherwise) }\end{array}$ & 0.162 & 1.31 & - & - \\
\hline Standard deviation of parameter distribution & 0.227 & 3.49 & - & - \\
\hline $\begin{array}{l}\text { Ethnicity indicator (1 if the respondent is Caucasian, } 0 \\
\text { otherwise) }\end{array}$ & - & - & -0.359 & -3.12 \\
\hline $\begin{array}{l}\text { Education indicator ( } 1 \text { if the respondent has a technical } \\
\text { college degree or a college degree, } 0 \text { otherwise) }\end{array}$ & - & - & -0.211 & -1.70 \\
\hline Standard deviation of parameter distribution & - & - & 0.239 & 3.30 \\
\hline \multicolumn{5}{|l|}{ Opinions and Preferences } \\
\hline $\begin{array}{l}\text { Familiarity with vehicle safety features indicator ( } 1 \text { if the } \\
\text { respondent is not familiar with advanced safety } \\
\text { features, } 0 \text { otherwise) }\end{array}$ & 0.317 & 1.51 & - & - \\
\hline Standard deviation of parameter distribution & 0.962 & 3.61 & - & - \\
\hline $\begin{array}{l}\text { Speed limit opinion indicator ( } 1 \text { if the respondent } \\
\text { disagrees or completely disagrees with the statement: } \\
\text { "Speed limits on high speed freeways should only be } \\
\text { suggestive", } 0 \text { otherwise) }\end{array}$ & - & - & -0.305 & -2.89 \\
\hline $\begin{array}{l}\text { Driver preference indicator ( } 1 \text { if the respondent is not } \\
\text { sure about driving herself/himself when there are more } \\
\text { than two licensed drivers in a vehicle on a trip, } 0 \\
\text { otherwise) }\end{array}$ & 0.442 & 2.81 & 0.439 & 2.47 \\
\hline $\begin{array}{l}\text { Mileage indicator ( } 1 \text { if the respondent annually drives } \\
\text { more than } 15,000 \text { miles, } 0 \text { otherwise) }\end{array}$ & 0.229 & 1.72 & - & - \\
\hline Cross equation correlation (t-stat in parentheses) & \multicolumn{4}{|c|}{$0.928(43.21)$} \\
\hline Number of survey distributors & \multicolumn{4}{|c|}{34} \\
\hline Number of respondents & \multicolumn{4}{|c|}{464} \\
\hline Log-likelihood at convergence & \multicolumn{4}{|c|}{-451.40} \\
\hline Log-likelihood at zero & \multicolumn{4}{|c|}{-668.30} \\
\hline Akaike information criterion (AIC) & \multicolumn{4}{|c|}{930.8} \\
\hline
\end{tabular}




\begin{tabular}{|c|c|c|}
\hline \multicolumn{3}{|c|}{ Aggregate distributional effect of random parameters across the respondents } \\
\hline & Above zero & Below zero \\
\hline $\begin{array}{l}\text { Gender indicator ( } 1 \text { if the respondent is male, } 0 \\
\text { otherwise) }\end{array}$ & $76.23 \%$ & $23.77 \%$ \\
\hline $\begin{array}{l}\text { Education indicator ( } 1 \text { if the respondent has a technical } \\
\text { college degree or a college degree, } 0 \text { otherwise) }\end{array}$ & $18.87 \%$ & $81.13 \%$ \\
\hline $\begin{array}{l}\text { Familiarity with vehicle safety features indicator ( } 1 \text { if the } \\
\text { respondent is not familiar with advanced safety } \\
\text { features, } 0 \text { otherwise) }\end{array}$ & $62.91 \%$ & $37.09 \%$ \\
\hline
\end{tabular}


Table 8. (Pseudo-)elasticities of the explanatory variables included in the model of individuals' concerns regarding security against hackers/terrorists and personal information privacy (Location/destination monitoring)

Variable

Security against hackers/terrorists
Personal information privacy (Location/destination monitoring)

\section{Socio-demographics}

Age indicator (1 if the respondent is younger than 25, 0 otherwise)

Gender indicator ( 1 if the respondent is male, 0 otherwise)

Ethnicity indicator (1 if the respondent is Caucasian, 0 otherwise)

Education indicator ( 1 if the respondent has a technical college degree or a college degree, 0 otherwise)

0.078

0.034

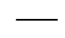

$-0.129$

$-0.094$

Opinions and Preferences

Familiarity with vehicle safety features indicator (1 if the respondent is not familiar with advanced safety features, 0 otherwise)

Speed limit opinion indicator (1 if the respondent disagrees or completely disagrees with the statement: "Speed limits on high speed freeways should only be suggestive”, 0 otherwise)

Driver preference indicator ( 1 if the respondent is not sure about driving herself/himself when there are more than two licensed drivers in a vehicle on a trip, 0 otherwise)

Mileage indicator ( 1 if the respondent annually drives more than 15,000 miles, 0 otherwise)
0.113

0.143

0.101

$-0.186$
0.126 
Table 9. Estimation results of the grouped random parameters binary probit model with heterogeneity in means of individuals' perceptions towards the use of existing FAA regulations for air traffic control to improve security against hackers/terrorists.

\begin{tabular}{|c|c|c|}
\hline Variable & Coeff. & $t$-stat \\
\hline \multicolumn{3}{|l|}{ Socio-demographics } \\
\hline Age indicator ( 1 if the respondent is younger than 30,0 otherwise) & 0.542 & 3.39 \\
\hline Ethnicity indicator ( 1 if the respondent is Asian, 0 otherwise) & 0.433 & 1.68 \\
\hline Standard deviation of parameter distribution & 1.462 & 4.12 \\
\hline $\begin{array}{l}\text { Income indicator ( } 1 \text { if the respondent's annual household income is } \\
\text { between } \$ 50,000 \text { and } \$ 150,000,0 \text { otherwise) }\end{array}$ & 0.391 & 2.66 \\
\hline \multicolumn{3}{|l|}{ Opinions and Preferences } \\
\hline $\begin{array}{l}\text { Driving speed indicator ( } 1 \text { if the respondent normally drives faster than } \\
65 \mathrm{mph} \text { on an interstate with a } 65 \mathrm{mph} \text { speed limit and little traffic, } 0 \\
\text { otherwise) }\end{array}$ & -0.468 & -2.40 \\
\hline $\begin{array}{l}\text { Driver preference indicator ( } 1 \text { if the respondent is not sure about driving } \\
\text { herself/himself when there are more than two licensed drivers in a } \\
\text { vehicle on a trip, } 0 \text { otherwise) }\end{array}$ & 0.487 & 3.12 \\
\hline $\begin{array}{l}\text { Accident history indicator ( } 1 \text { if the respondent has had more than one } \\
\text { non-severe accidents in the last } 5 \text { years, } 0 \text { otherwise) }\end{array}$ & -0.457 & -1.86 \\
\hline Annual mileage driven (in 1000 miles) & -0.016 & -1.44 \\
\hline Standard deviation of parameter distribution & 0.012 & 2.35 \\
\hline \multicolumn{3}{|l|}{ Heterogeneity in means } \\
\hline $\begin{array}{l}\text { Annual mileage driven (in } 1000 \text { miles): Education indicator ( } 1 \text { if the } \\
\text { respondent has a college degree or post graduate degree, } 0 \text { otherwise) }\end{array}$ & 0.027 & 2.46 \\
\hline Number of survey distributors & \multicolumn{2}{|c|}{34} \\
\hline Number of respondents & \multicolumn{2}{|c|}{451} \\
\hline Log likelihood function & \multicolumn{2}{|c|}{-268.72} \\
\hline Log-likelihood at zero & \multicolumn{2}{|c|}{-355.06} \\
\hline Akaike information criterion (AIC) & \multicolumn{2}{|c|}{557.40} \\
\hline \multicolumn{3}{|c|}{ Aggregate distributional effect of random parameters across the respondents } \\
\hline & $\begin{array}{c}\text { Above } \\
\text { zero }\end{array}$ & $\begin{array}{c}\text { Below } \\
\text { zero }\end{array}$ \\
\hline Ethnicity indicator (1 if the respondent is Asian, 0 otherwise) & $61.64 \%$ & $38.36 \%$ \\
\hline Annual mileage driven (in 1000 miles) & $9.12 \%$ & $90.88 \%$ \\
\hline
\end{tabular}


Table 10. (Pseudo-)elasticities of the explanatory variables included in the model of individuals' perceptions towards the use of existing FAA regulations for air traffic control to improve security against hackers/terrorists.

\section{Variable}

\section{Socio-demographics}

Age indicator (1 if the respondent is younger than 30, 0 otherwise)

Ethnicity indicator ( 1 if the respondent is Asian, 0 otherwise)

Income indicator (1 if the respondent's annual household income is between $\$ 50,000$ and $\$ 150,000,0$ otherwise)

\section{Opinions and Preferences}

Driving speed indicator ( 1 if the respondent normally drives faster than 65 mph on an interstate with a $65 \mathrm{mph}$ speed limit and little traffic, 0 otherwise)

Driver preference indicator (1 if the respondent is not sure (varies) about driving herself/himself when there are more than two licensed drivers in a vehicle on a trip, 0 otherwise)

Accident history indicator (1 if the respondent has had more than one nonsevere accidents in the last 5 years, 0 otherwise)

Annual mileage driven (in 1000 miles) 
Table 11. Estimation results of the correlated grouped random parameters binary probit model with heterogeneity in means of individuals' perceptions towards establishing air-road police enforcement (with flying police cars) to improve security against hackers/terrorists.

Variable

Constant

Socio-demographics

Education indicator ( 1 if the respondent has a technical college degree or a college degree, 0 otherwise)

Standard deviation of parameter distribution

Income indicator ( 1 if the respondent's annual household income is less than $\$ 75,000,0$ otherwise)

Opinions and Preferences

Familiarity with vehicle safety features indicator (1 if the respondent never owned a car with an advanced safety feature, 0 otherwise)

Aggressive driving indicator ( 1 if the respondent thinks that s/he normally drives not aggressively, 0 otherwise)

Speed limit opinion indicator ( 1 if the respondent completely agrees with the statement: "Speed limits on high speed freeways should only be suggestive", 0 otherwise)

Accident history indicator ( 1 if the respondent has had at least one non-severe or severe accident in the last 5 years, 0 otherwise)

Standard deviation of parameter distribution

Heterogeneity in means

Education indicator: Mileage indicator ( 1 if the respondent annually drives greater than 10,000 miles, 0 otherwise)

Number of survey distributors

Number of respondents

Log likelihood function

Log-likelihood at zero

Akaike information criterion (AIC)
Coeff. $\quad t$-stat

0.958

7.51

0.137

0.519

$-0.394$

$-1.86$

$-0.329$

0.407

$-0.426$

0.581

4.05

$-0.434$ $-2.04$

Aggregate distributional effect of random parameters across the respondents

\begin{tabular}{lc|c}
\hline & Above zero & Below zero \\
\hline $\begin{array}{l}\text { Education indicator (1 if the respondent has a technical } \\
\text { college degree or a college degree, 0 otherwise) }\end{array}$ & $60.41 \%$ & $39.59 \%$ \\
$\begin{array}{l}\text { Accident history indicator (1 if the respondent has had at } \\
\text { least one non-severe or severe accident in the last 5 years, } \\
0 \text { otherwise) }\end{array}$ & $24.02 \%$ & $75.98 \%$ \\
\hline
\end{tabular}


Elements of the Cholesky Matrix [t-stats in brackets], and correlation coefficients (in parentheses) for the random parameters

\begin{tabular}{lcc} 
& Accident history & $\begin{array}{c}\text { Education } \\
\text { indicator }\end{array}$ \\
\hline \multirow{2}{*}{ Accident history indicator } & indicator & $-0.306[-2.68]$ \\
\multirow{2}{*}{ Education indicator } & $0.581[4.05]$ & $(-0.589)$ \\
& $-0.306[-2.68]$ & $0.419[3.85]$ \\
\hline
\end{tabular}


Table 12. (Pseudo-)elasticities of the explanatory variables included in the model of individuals' perceptions towards establishing air-road police enforcement (with flying police cars) to improve security against hackers/terrorists.

\section{Variable}

\section{Socio-demographics}

Education indicator ( 1 if the respondent has a technical college degree or a college degree, 0 otherwise)

Income indicator ( 1 if the respondent's annual household income is less than $\$ 75,000$, 0 otherwise)

\section{Opinions and Preferences}

Familiarity with vehicle safety features indicator (1 if the respondent never owned a car with an advanced safety feature, 0 otherwise)

Aggressive driving indicator ( 1 if the respondent thinks that s/he normally drives not aggressively, 0 otherwise)

Speed limit opinion indicator (1 if the respondent completely agrees with the statement: "Speed limits on high speed freeways should only be suggestive", 0 otherwise)

Accident history indicator ( 1 if the respondent has had at least one non-severe or severe accident in the last 5 years, 0 otherwise) 
Table 13. Estimation results of the correlated grouped random parameters binary probit model of individuals' perceptions towards detail profiling and background checking of flying car owners/operators to improve security against hackers/terrorists.

\begin{tabular}{|c|c|c|}
\hline Variable & Coeff. & $t$-stat \\
\hline Constant & 0.719 & 8.38 \\
\hline \multicolumn{3}{|l|}{ Socio-demographics } \\
\hline Age indicator ( 1 if the respondent is older than 50,0 otherwise) & -0.428 & -1.87 \\
\hline Ethnicity indicator ( 1 if the respondent is Asian, 0 otherwise) & 0.540 & 2.48 \\
\hline $\begin{array}{l}\text { Income indicator ( } 1 \text { if the respondent's annual household income is } \\
\text { greater than } \$ 100,000,0 \text { otherwise) }\end{array}$ & 0.280 & 1.28 \\
\hline Standard deviation of parameter distribution & 0.776 & 26.26 \\
\hline \multicolumn{3}{|l|}{ Opinions and Preferences } \\
\hline $\begin{array}{l}\text { Mileage indicator ( } 1 \text { if the respondent annually drives less than 5,000 } \\
\text { miles, } 0 \text { otherwise) }\end{array}$ & -0.026 & -0.12 \\
\hline Standard deviation of parameter distribution & 0.551 & 2.54 \\
\hline Number of survey distributors & \multicolumn{2}{|c|}{34} \\
\hline Number of respondents & \multicolumn{2}{|c|}{466} \\
\hline Log likelihood function & \multicolumn{2}{|c|}{-239.62} \\
\hline Log-likelihood at zero & \multicolumn{2}{|c|}{-300.02} \\
\hline Akaike information criterion (AIC) & \multicolumn{2}{|c|}{495.2} \\
\hline
\end{tabular}

\begin{tabular}{|c|c|c|}
\hline \multicolumn{3}{|c|}{ Aggregate distributional effect of random parameters across the respondents } \\
\hline & Above zero & Below zero \\
\hline $\begin{array}{l}\text { Income indicator ( } 1 \text { if the respondent's annual household income is } \\
\text { greater than } \$ 100,000,0 \text { otherwise) }\end{array}$ & $64.09 \%$ & $35.91 \%$ \\
\hline $\begin{array}{l}\text { Mileage indicator ( } 1 \text { if the respondent annually drives less than 5,000 } \\
\text { miles, } 0 \text { otherwise) }\end{array}$ & $48.12 \%$ & $51.88 \%$ \\
\hline \multicolumn{3}{|c|}{$\begin{array}{l}\text { Elements of the Cholesky Matrix [t-stats in brackets], and correlation coefficients (in } \\
\text { parentheses) for the random parameters }\end{array}$} \\
\hline & $\begin{array}{l}\text { Mileage } \\
\text { indicator }\end{array}$ & $\begin{array}{l}\text { Income } \\
\text { indicator }\end{array}$ \\
\hline Mileage indicator & $\begin{array}{l}0.551[2.54] \\
\quad(1.000)\end{array}$ & $\begin{array}{l}0.622[2.86] \\
\quad(0.801)\end{array}$ \\
\hline Income indicator & $\begin{array}{l}0.622[2.86] \\
\quad(0.801)\end{array}$ & $\begin{array}{l}0.464[2.33] \\
(1.000)\end{array}$ \\
\hline
\end{tabular}


Table 14. (Pseudo-) elasticities of the explanatory variables included in the model of individuals' perceptions towards detail profiling and background checking of flying car owners/operators to improve security against hackers/terrorists.

\section{Variable}

\section{Socio-demographics}

Age indicator (1 if the respondent is older than 50, 0 otherwise)

Ethnicity indicator (1 if the respondent is Asian, 0 otherwise)

Income indicator ( 1 if the respondent's annual household income is greater than $\$ 100,000,0$ otherwise)

\section{Opinions and Preferences}

Mileage indicator ( 1 if the respondent annually drives less than 5,000 miles, 0 otherwise) 
Table 15. Estimation results of the correlated grouped random parameters binary probit model of individuals' perceptions towards establishing no-fly zones for flying cars near sensitive locations (military bases, power/energy plants, governmental buildings, major transportation hubs, etc.).

\begin{tabular}{|c|c|c|}
\hline Variable & Coeff. & t-stat \\
\hline Constant & 1.235 & 2.37 \\
\hline \multicolumn{3}{|l|}{ Socio-demographics } \\
\hline Age indicator ( 1 if the respondent is younger than 30,0 otherwise) & -0.937 & -2.09 \\
\hline Ethnicity indicator ( 1 if the respondent is Caucasian, 0 otherwise) & -0.154 & -0.87 \\
\hline Standard deviation of parameter distribution & 0.522 & 3.32 \\
\hline $\begin{array}{l}\text { No. of children indicator ( } 1 \text { if the respondent's household has no child } \\
\text { aged below } 6 \text { years, } 0 \text { otherwise) }\end{array}$ & 0.839 & 2.64 \\
\hline Standard deviation of parameter distribution & 0.605 & 23.86 \\
\hline \multicolumn{3}{|l|}{ Opinions and Preferences } \\
\hline $\begin{array}{l}\text { Driving experience indicator ( } 1 \text { if the respondent has a driving license } \\
\text { for over } 15 \text { years, } 0 \text { otherwise) }\end{array}$ & -1.034 & -2.08 \\
\hline $\begin{array}{l}\text { Driver preference indicator ( } 1 \text { if the respondent generally prefers to } \\
\text { have the other driver drive when there are more than two licensed } \\
\text { drivers in a vehicle on a trip, } 0 \text { otherwise) }\end{array}$ & -0.499 & -2.68 \\
\hline $\begin{array}{l}\text { Speed limit opinion indicator ( } 1 \text { if the respondent is neutral with the } \\
\text { statement: "Speed limits on high speed freeways should only be } \\
\text { suggestive", } 0 \text { otherwise) }\end{array}$ & 0.318 & 1.69 \\
\hline Number of survey distributors & \multicolumn{2}{|c|}{34} \\
\hline Number of respondents & \multicolumn{2}{|c|}{485} \\
\hline Log likelihood function & \multicolumn{2}{|c|}{-215.86} \\
\hline Log-likelihood at zero & \multicolumn{2}{|c|}{-274.27} \\
\hline Akaike information criterion (AIC) & \multicolumn{2}{|c|}{451.7} \\
\hline
\end{tabular}

\begin{tabular}{|c|c|c|}
\hline \multicolumn{3}{|c|}{ Aggregate distributional effect of random parameters across the respondents } \\
\hline & Above zero & Below zero \\
\hline Ethnicity indicator ( 1 if the respondent is Caucasian, 0 otherwise) & $38.40 \%$ & $61.60 \%$ \\
\hline $\begin{array}{l}\text { No. of children indicator ( } 1 \text { if the respondent's household has no } \\
\text { child aged below } 6 \text { years, } 0 \text { otherwise) }\end{array}$ & $91.72 \%$ & $8.28 \%$ \\
\hline \multicolumn{3}{|c|}{$\begin{array}{l}\text { Elements of the Cholesky Matrix [t-stats in brackets], and correlation coefficients (in } \\
\text { parentheses) for the random parameters }\end{array}$} \\
\hline & $\begin{array}{l}\text { Ethnicity } \\
\text { indicator }\end{array}$ & $\begin{array}{c}\text { No. of } \\
\text { children } \\
\text { indicator }\end{array}$ \\
\hline Ethnicity indicator & $\begin{array}{l}0.522[3.32] \\
\quad(1.000)\end{array}$ & $\begin{array}{l}-0.561[-4.12] \\
(-0.926)\end{array}$ \\
\hline No. of children indicator & $\begin{array}{l}-0.561[-4.12] \\
(-0.926)\end{array}$ & $\begin{array}{l}0.228[2.80] \\
(1.000)\end{array}$ \\
\hline
\end{tabular}


Table 16. (Pseudo-)elasticities of the explanatory variables included in the model of individuals' perceptions towards establishing no-fly zones for flying cars near sensitive locations (military bases, power/energy plants, governmental buildings, major transportation hubs, etc.).

\section{Variable}

\section{Socio-demographics}

Age indicator (1 if the respondent is younger than 30, 0 otherwise)

Ethnicity indicator ( 1 if the respondent is Caucasian, 0 otherwise)

No. of children indicator ( 1 if the respondent's household has no child aged below 6 years, 0 otherwise)

\section{Opinions and Preferences}

Driving experience indicator ( 1 if the respondent has a driving license for over 15 years, 0 otherwise)

Driver preference indicator ( 1 if the respondent generally prefers to have the other driver drive when there are more than two licensed drivers in a vehicle on a trip, 0 otherwise)

Speed limit opinion indicator (1 if the respondent is neutral with the statement: "Speed limits on high speed freeways should only be suggestive", 0 otherwise) 
A number of sociodemographic characteristics are found to affect individuals’ securityspecific perceptions. Table 7 shows that $76.23 \%$ of the male respondents are concerned about security against hackers/terrorists after the introduction of flying cars, while the opposite is observed for the remaining $23.77 \%$. With regard to the variables reflecting the age of the respondents, respondents who are younger than 25 years old are more likely to be concerned (by 0.078, as indicated by the (pseudo-)elasticities in Table 8) about security against hackers/terrorists. Similarly, individuals younger than 30 years old are more likely to believe (by 0.173 , as indicated in Table 10) that the use of existing FAA regulations for air traffic control can improve flying cars' security against hackers/terrorists. Interestingly, the same group of individuals are less likely to believe (by -0.170 , as indicated in Table 16) that the establishment of no-fly zones near sensitive locations can improve security. As far as older individuals are concerned, respondents who are older than 50 are less likely (by -0.138 , as indicated by the (pseudo-)elasticities in Table 14) to anticipate security enhancement against hackers/terrorists with detailed profiling and background checking of flying car owners/operators. Similar to their perceptions on the safety-related implications of flying cars, older individuals may be over-reserved against the technological features that can breach their privacy and, hence, may not be easily convinced about the effectiveness of passive security measures, such as the background checking.

The majority (61.64\%, as indicated in Table 9) of the Asian individuals are more likely to be in favor of using the existing FAA regulations for air traffic control, while the opposite is observed for the remaining 38.36\%. In line with the previous finding, Asian individuals are also more likely (by 0.128 , as indicated by the (pseudo-) elasticities in Table 14) to expect that the detailed profiling and background checking of flying car owners/operators can enhance security against hackers/terrorists. As far as Caucasian individuals are concerned, they are less likely (by 
-0.129 , as indicated in Table 8) to perceive personal information privacy as a concern. However, the majority (61.60\%, as shown in Table 15) of these individuals do not perceive establishment of no-fly zones as a credible security measure; whereas the remaining $38.40 \%$ believe the opposite.

Focusing on the effect of the educational background, the vast majority (81.13\%, as shown in Table 7) of the respondents who have a technical college degree or a college degree are less likely to be concerned about personal information privacy (location/destination monitoring) with the future introduction of flying cars; whereas the opposite is observed for the remaining $18.87 \%$. The majority (60.41\%, as indicated in Table 11 ) of the respondents from same educational background are more likely to believe that the establishment of air-road police enforcement has the potential to improve security against hackers/terrorists. The opposite effect is observed for the remaining $39.59 \%$ of the individuals. Note that this explanatory variable also produced statistically significant heterogeneity in means. Specifically, the high annual mileage indicator (greater than 10,000 miles) is found to decrease the mean of the random parameter relating to the education indicator, which, in turn, leads to a lower likelihood of expectations for security enhancement. The driving experience gained by greater annual mileage may make the individuals more aware about possible technical challenges that need to be overcome for the combination of the on-ground and in-air enforcement. As such, greater annual mileage imposes an additional layer of heterogeneity on the perceptions of well-educated individuals as well as a more balanced distribution of favorable and non-favorable perceptions towards the effectiveness of air-road police enforcement.

The household income level of individuals constitutes another significant determinant of security-related perceptions. For example, individuals from low and medium income households (i.e., with annual household income less than $\$ 75,000$ ) are less likely (by -0.088 , as indicated in 
Table 12) to believe that establishing air-road police enforcement is going to improve security against hackers/terrorists. On the contrary, individuals from medium to high income households (i.e., with annual household income between $\$ 50,000$ and $\$ 150,000$ ) are more likely (by 0.130 , as indicated in Table 10) to believe that use of existing FAA regulations for air traffic control would improve security. In line with this finding, 64.09\% individuals from high income households (i.e., with annual household income greater than $\$ 100,000$ ) are more likely to believe that detail profiling and background checking of flying car owners/operators would improve security against hackers/terrorists; whereas the opposite is observed for the rest $35.91 \%$ as indicated in Table 13 . Overall, members of low income households appear to be more skeptical against the effectiveness of possible security measures. Their non-favorable perceptions regarding the security implications of flying cars are in line with their low willingness to use the flying cars and their low expectations about the mobility benefits that will arise after the introduction of flying cars (see also Eker et al., 2019a; Eker et al., 2019b). The majority of respondents from medium to high income households seem more inclined to endorse various security measures. This trend is expected, since such individuals are considered as more likely to use the flying cars (see also Eker et al., 2019a), and generally more likely to adopt emerging transportation technologies (see also Alemi et al., 2018). It was also observed that $91.72 \%$ of respondents from households having no children aged below 6 years old are more likely to believe that establishing no-fly zone for flying cars near sensitive locations is going to improve security; whereas the remaining $8.28 \%$ respondents believe the opposite, as indicated in Table 7. This finding may refer to the subdued skepticism towards security issues as well as optimistic outlook towards potential security measures of individuals from such households, arising from the absence of young child - which is one of the most vulnerable population groups with regard to any security issues. 
As far as the familiarity with advanced transportation technologies is concerned, $62.91 \%$ of the respondents who are not familiar with the use of vehicle safety features are intuitively more concerned about the security against hackers/terrorists, while the opposite is observed for the remaining 37.09\%, as indicated in Table 7. Individuals who never owned a car with advanced safety features are less likely (by -0.092 as shown in Table 12) to expect improvements in security with the establishment of air-road police enforcement. In line with earlier research findings (see also Eker et al., 2019b), the non-familiarity of individuals with existing, yet advanced transportation technologies may inflate their skepticism against implications of flying cars with significant uncertainties, especially in the context of safety and security.

Moving to the behavioral and attitudinal characteristics, respondents who perceive themselves as nonaggressive drivers are found to be more supportive (by 0.123 , as shown in Table 12) of establishing air-road police enforcement. This finding may capture underlying behavioral patterns of the specific individuals, primarily with respect to their response against various aspects of traffic enforcement (see also Fountas et al., 2019). Drivers with self-reported speeding behavior (e.g., drivers who normally drive faster than $65 \mathrm{mph}$ on an interstate with speed limit of $65 \mathrm{mph}$ and little traffic) are less likely (by -0.142 , as shown in Table 10) to expect that the use of existing FAA regulations will improve security.

Furthermore, individuals who do not endorse the suggestive role of speed limits are less concerned (by -0.186, as shown in Table 8) about personal information and privacy issues after the introduction of flying cars. In contrast, the respondents that stand in favor of the suggestive speed limits are less likely (by -0.121 , as shown in Table 12) to expect security improvements with the establishment of air-road police enforcement. In addition, respondents who are neutral with the suggestive role of speed limits are more likely (by 0.068, as shown in Table 16) to anticipate 
improvements in security after the establishment of no-fly zones near sensitive locations. Overall, individuals’ perceptions on the role of speed limit may again pick up their attitudinal perspectives regarding the traffic enforcement, with the latter possibly driving their expectations for the safety implications of flying cars. For example, individuals supporting the suggestive speed limits may have more critical viewpoints on the effectiveness of traffic enforcement, which may be reflected on their expectations about the security potential of the air-road enforcement.

Another source of perceptual variations arises from individuals with skepticism to drive in shared trips (e.g., drivers who are not sure about driving when other licensed drivers are also present in a vehicle). These individuals are more likely (by 0.143 and 0.101 , as shown in Table 8) to be concerned about security against hackers/terrorists and privacy issues after the introduction of flying cars, respectively. Respondents from the same group are more likely (by 0.152, as shown in Table 10) to anticipate that the existing FAA regulations for air traffic control will improve security against hackers/terrorists. Moreover, respondents who prefer to have someone else drive in a similar scenario are less likely (by -0.124 , as shown in Table 16) to expect improvements in security with the establishment of no-fly zones for flying cars near sensitive locations. These results show that the lack of driving confidence stemming from individuals' skepticism to drive may inflate possible concerns about the security performance of flying cars. Taking into account the causal relationship between driving confidence and risk perception (see also Sundström, 2011, Fountas et al., 2019), this finding is intuitive and may be applicable to the entire perceptual spectrum of this group of individuals.

Respondents who were involved in more-than-one non-severe accidents over the last 5 years are less likely (by -0.086 , as shown in Table 10) to expect that the existing FAA regulations for air traffic control will improve security against hackers/terrorists. Similarly, $75.98 \%$ of the 
respondents who were involved in at least one non-severe or severe accident over the last 5 years are less likely to expect that the air-road police enforcement will improve security against hackers/terrorists (as shown in Table 11), while the opposite is observed for the remaining 24.02\%. The undesirable circumstances arising from a previous accident experience may escalate individuals' skeptical perceptions towards intrusive, yet preventive security measures. Furthermore, individuals with high annual mileage (more than 15,000 miles per year) are more likely (by 0.126 , as shown in Table 8 ) to be concerned about security against hackers/terrorists from the future use of flying cars. Similarly, respondents who have had a driving license for over 15 years are less likely (by -0.279 , as shown in Table 16) to expect improved security through establishing no-fly zones for flying cars near sensitive locations.

The annual mileage constitutes a significant source of unobserved heterogeneity in the model of individuals' perceptions about the use of the existing FAA air traffic regulations. Specifically, for $90.88 \%$ of the responses (as indicated in Table 9), the variable reflecting the annual mileage driven, decreases the individuals' likelihood to expect that the existing FAA regulations for air traffic control will improve security against hackers/terrorists. Apart from heterogeneity in the model parameters, the annual mileage driven resulted in statistically significant heterogeneity in means. The high education indicator (college or post-graduate degree) is found to increase the mean of the random parameter distribution of the annual mileage, which, in turn, results in an increase in the likelihood of favorable expectations towards the use of FAA regulations. In other words, well-educated and experienced drivers may still have mixed, but more balanced attitudinal perspectives towards the effectiveness of FAA air traffic regulations. On the contrary, $51.88 \%$ of the individuals with low annual mileage (less than 5,000 miles per year) are less likely to believe that the detailed profiling and background checking of flying car 
owners/operators will improve security against hackers/terrorists, while the opposite is observed for the remaining 48.12\%. Despite their mixed perceptions, less experienced drivers may expect the imposition of more intrusive measures as a warrant for their security during the flying car trips.

Focusing on the interactive effect of unobserved characteristics, education indicator (reflecting technical college degree or college degree) and the accident history indicator (reflecting involvement in at least one accident over the last 5 years) produced correlated random parameters in the model of individuals' perceptions towards the establishment of air-road police enforcement. The correlation coefficient is negative $(-0.589$, as shown in Table 11), indicating that the commonly shared unobserved characteristics captured by these two random parameters have heterogeneous effect on individuals' perceptions. In the model of individuals' perception towards detail profiling and background checking, the income indicator (reflecting annual household income above $\$ 100,000$ ) and the mileage indicator (reflecting annual driving mileage less than 5,000 miles) both resulted in correlated random parameters with a positive correlation coefficient (0.801, as shown in Table 13). The latter implies that the effect of the unobserved characteristics captured by the aforementioned random parameters on individuals' perspective is homogeneous. The ethnicity indicator (reflecting Caucasian respondents) and the number of children indicator (reflecting respondents from households with no children aged less than 6 years old) also resulted in correlated random parameters in the model of individuals' perception towards establishing nofly zones for flying cars near sensitive locations. In this case, the correlation coefficient is negative (-0.926, as indicated in table 15), demonstrating a heterogeneous effect on perceptual mechanism of Caucasian individuals from households with no children less than 6 years old. 


\section{SUMMARY AND CONCLUSION}

Unlike with the high commercial readiness of flying cars, the implications of their safety and security features on public perception are still highly uncertain. Once flying cars start to penetrate the surface and air transportation networks, various operational and regulating policies are expected to take effect. The effectiveness of such policies will be primarily determined by their potential to fulfill public expectations and to ensure the commercial viability of this new technology. In this context, this paper aims at identifying - at an exploratory level - various nuances of public perception towards the safety benefits as well as the safety and security concerns that may arise after the emergence of flying cars. To that end, an online survey was conducted and socio-demographic information as well as opinions and preferences regarding flying cars were gained from 584 individuals.

Due to the emerging nature of this technology, the opinions and expectations towards the implications of flying cars may be significantly affected by complex patterns of unobserved heterogeneity. To tackle this issue, several layers of unobserved heterogeneity were accounted for in the statistical analysis of survey responses, namely: (i) commonly shared unobserved variations across conceptually interrelated perceptions; (ii) unobserved heterogeneity variations and interactions across panel-specific responses; and (iii) heterogeneity in the means of random parameters. To determine the factors affecting perceived safety benefits as well as safety- and security-related concerns, the grouped random parameters bivariate probit modeling framework was employed. To identify the factors affecting respondents' opinions regarding measures that can possibly enhance security in the operation of flying cars, various correlated grouped random parameters binary probit models with heterogeneity in means were estimated. 
The results of the statistical analysis show that a number of socio-demographic and attitudinal characteristics, behavioral traits, and driving habits may influence the respondents' opinions towards safety- and security-related perceptions. Overall, the results showed that younger respondents seem to be more welcoming towards the safety benefits of flying cars and to possible security-related measures, as opposed to older individuals who were consistently found concerned about various safety and security issues. Education and income level were repeatedly identified as sources of unobserved heterogeneity resulting in random parameters and, hence, mixed perceptual patterns. It should be noted that the education level was found to produce highly heterogeneous effects, not only across the survey responses, but also across the means of random parameters. Asian respondents stand generally more favorably towards the safety benefits of flying cars and the suggested security countermeasures. Lack of familiarity with advanced vehicle features is found to increase individuals' skepticism towards the safety and security performance of flying cars. In addition, several driving-related opinions and behavioral patterns are also found to affect individuals' perceptions. Specifically, the driving experience, as reflected by the annual mileage driven, constitutes an additional source of perceptual variations introducing heterogeneity in the effect of explanatory variables across the responses as well as heterogeneity in the means of random parameters. The estimation of correlated grouped random parameters also enabled the identification of various inter-dependencies in the perceptual mechanisms of Caucasian individuals, medium-or well-educated individuals, medium or high income individuals, individuals with accident history, individuals with low annual driving mileage, and individuals from households without children.

Despite the several challenges arising from the uncertainty accompanying public perceptions, the findings of this study highlight the major role of safety and security, as sources of 
concern for individuals that are seemingly less appealed by emerging transportation technologies. Such groups may include older individuals, low-income individuals and individuals with accident experience. However, the integration of flying cars in the existing transportation network can be ensured only if the public confidence on safety and security of flying cars is broadly consolidated, including the groups of less favorable, yet potential travelers. The key perceptions of the latter, as reflected by the findings of this study, can assist in the formation of partnerships between legislative entities, manufacturers and service providers with specific focus on enhancing public confidence through outreach campaigns or traveler-centered regulating policies.

\section{ACKNOWLEDGEMENTS}

The contents of this paper reflect the views of the authors, who are responsible for the facts and the accuracy of the data presented herein. The contents do not necessarily reflect the official views or policies of any agency, nor do the contents constitute a standard, specification, or regulation. 


\section{REFERENCES}

Ahmed, S.S., Fountas, G., Eker, U., Still, S., Anastasopoulos, P.Ch., 2019. An exploratory empirical analysis of willingness to hire and pay for flying taxis and shared flying car services. Working paper.

Airbus., 2018. Vahana, the Self-Piloted, eVTOL aircraft from A3 by Airbus, Successfully Completes First Full-Scale Test Flight. Available at: https://www.airbus.com/newsroom/pressreleases/en/2018/02/vahana--the-self-piloted--evtol-aircraft-from-a--by-airbus--succ.html.

Akyelken, N., Givoni, M., Salo, M., Plepys, A., Jachym, J., Anderton, K., Koskela, S., 2018. The importance of institutions and policy settings for car sharing - Evidence from the UK, Israel, Sweden and Finland. European Journal of Transport and Infrastructure Research, 18, 340-359.

Alemi, F., Circella, G., Handy, S., Mokhtarian, P., 2018. What influences travelers to use Uber? Exploring the factors affecting the adoption of on-demand ride services in California. Travel Behaviour and Society, 13, 88-104.

Amoh-Gyimah, R., Saberi, M., Sarvi, M., 2017. The effect of variations in spatial units on unobserved heterogeneity in macroscopic crash models. Analytic Methods in Accident Research, 13, 28-51.

Anastasopoulos, P.Ch. 2016. Random parameters multivariate tobit and zero-inflated count data models: Addressing unobserved and zero-state heterogeneity in accident injury-severity rate and frequency analysis. Analytic Methods in Accident Research, 11, 17-32.

Anastasopoulos, P.Ch., Fountas, G., Sarwar, M.T., Karlaftis, M.G., Sadek, A.W., 2017. Transport habits of travelers using new energy type modes: a random parameters hazard-based approach of travel distance. Transportation Research Part C, 77, 516-528. 
Balusu, S.K., Pinjari, A.R., Mannering, F.L., Eluru, N., 2018. Non-decreasing threshold variances in mixed generalized ordered response models: A negative correlations approach to variance reduction. Analytic Methods in Accident Research, 20, 46-67.

Bansal, P., Kockelman, K.M., Singh, A., 2016. Assessing public opinions of and interest in new vehicle technologies: An Austin perspective. Transportation Research Part C, 67, 1-14.

Bansal, P., Kockelman, K.M., 2018. Are we ready to embrace connected and self-driving vehicles? A case study of Texans. Transportation, 45(2), 641-675.

Barbour, N., Zhang, Y., Mannering, F., 2019. A statistical analysis of bike sharing usage and its potential as an auto-trip substitute. Journal of Transport and Health, 12, 253-262.

Bartolini, C., Tettamanti, T., Varga, I., 2017. Critical features of autonomous road transport from the perspective of technological regulation and law. Transportation Research Procedia, 27, 791-798.

Becker, E. P., 2017. The future of flying is near: Materials engineering and tribology are two big factors when considering flying cars. Tribology and Lubrication Technology, 73, 96-96.

Becker, F., Axhausen, K.W., 2017. Literature review on surveys investigating the acceptance of automated vehicles. Transportation, 44(6), 1293-1306.

Behnood, A., Mannering, F., 2017a. The effect of passengers on driver-injury severities in singlevehicle crashes: a random parameters heterogeneity-in-means approach. Analytic Methods in Accident Research, 14, 41-54.

Behnood, A., Mannering, F., 2017b. Determinants of bicyclist injury severities in bicycle-vehicle crashes: A random parameters approach with heterogeneity in means and variances. Analytic Methods in Accident Research, 16, 35-47.

Bordagaray, M., dell’Olio, L., Fonzone, A., Ibeas, Á., 2016. Capturing the conditions that 
introduce systematic variation in bike-sharing travel behavior using data mining techniques. Transportation Research Part C, 71, 231-248.

Cai, Q., Abdel-Aty, M., Lee, J., Wang, L., Wang, X., 2018. Developing a grouped random parameters multivariate spatial model to explore zonal effects for segment and intersection crash modeling. Analytic Methods in Accident Research, 19, 1-15.

Combs, T.S., Sandt, L.S., Clamann, M.P., McDonald, N.C., 2019. Automated Vehicles and Pedestrian Safety: Exploring the Promise and Limits of Pedestrian Detection. American Journal of Preventive Medicine, 56, 1-7.

Cui, J., Liew, L.S., Sabaliauskaite, G., Zhou, F., 2018. A Review on Safety Failures, Security Attacks, and Available Countermeasures for Autonomous Vehicles. Ad Hoc Networks.

De La Torre, G., Rad, P., Choo, K.K.R., 2018. Driverless vehicle security: Challenges and future research opportunities. Future Generation Computer Systems.

Eker, U., Fountas, G., Anastasopoulos, P.Ch., 2019a. A preliminary investigation of public's expectations and interest in flying cars: a statistical analysis of willingness to pay and willingness to use flying cars. Working paper.

Eker, U., Fountas, G., Anastasopoulos, P.Ch., Still, S.E., 2019b. An exploratory investigation of public perceptions towards key benefits and concerns from the future use of flying cars. Working paper.

Faghih-Imani, A., Anowar, S., Miller, E.J., Eluru, N., 2017. Hail a cab or ride a bike? A travel time comparison of taxi and bicycle-sharing systems in New York City. Transportation Research Part A, 101, 11-21.

Fagnant, D. J., Kockelman, K., 2015. Preparing a nation for autonomous vehicles: opportunities, barriers and policy recommendations. Transportation Research Part A, 77, 167-181. 
Fagnant, D. J., Kockelman, K. M., 2016. Dynamic ride-sharing and fleet sizing for a system of shared autonomous vehicles in Austin, Texas. Transportation, 45, 143-158.

Fountas, G., Anastasopoulos, P.Ch., 2017. A random thresholds random parameters hierarchical ordered probit analysis of highway accident injury-severities. Analytic Methods in Accident Research, 15, 1-16.

Fountas, G., 2018. Stationary and time-varying factors affecting highway accident occurrence and injury-severity: Addressing unobserved heterogeneity with alternate random parameters and latent class models. Ph.D. Dissertation, University at Buffalo, The State University of New York. Buffalo, New York.

Fountas, G., Anastasopoulos, P.Ch., 2018. Analysis of accident injury-severity outcomes: The zero-inflated hierarchical ordered probit model with correlated disturbances. Analytic Methods in Accident Research, 20, 30-45.

Fountas, G., Anastasopoulos, P.Ch., Mannering, F.L., 2018a. Analysis of vehicle accident-injury severities: A comparison of segment- versus accident-based latent class ordered probit models with class-probability functions. Analytic Methods in Accident Research, 18, 1532.

Fountas, G., Anastasopoulos, P.Ch., Abdel-Aty, M, 2018b. Analysis of accident injury-severities using a correlated random parameters ordered probit approach with time variant covariates. Analytic Methods in Accident Research, 18, 57-68.

Fountas, G., Sarwar, M., Anastasopoulos, P.Ch., Blatt, A., Majka, K., 2018c. Analysis of stationary and dynamic factors affecting highway accident occurrence: a dynamic correlated random parameters binary logit approach. Accident Analysis and Prevention, $113,330-340$. 
Fountas, G., Pantangi, S.S., Hulme, K.F., Anastasopoulos, P.Ch., 2019. The effects of driver fatigue, gender, and distracted driving on perceived and observed aggressive driving behavior: A correlated grouped random parameters bivariate probit approach. Analytic Methods in Accident Research, 22, 100091.

Garikapati, V.M., Pendyala, R.M., Morris, E.A., Mokhtarian, P.L., McDonald, N., 2016. Activity patterns, time use, and travel of millennials: a generation in transition?. Transport Reviews, 36(5), 558-584.

Gkartzonikas, C., Gkritza, K., 2019. What have we learned? A review of stated preference and choice studies on autonomous vehicles. Transportation Research Part C, 98, 323-337.

Greene, W., 2016. LIMDEP Version 11.0. Econometric Software, Inc., Plainview, NY.

Greene, H.W., 2017. Econometric Analysis, 8th edn, Upper Saddle River, NJ: Pearson Education International.

Halton, J., 1960. On the efficiency of certain quasi-random sequences of points in evaluating multidimensional integrals. Numerische Mathematik, 2, 84-90.

Heydari, S., Fu, L., Thakali, L., Joseph, L., 2018. Benchmarking regions using a heteroskedastic grouped random parameters model with heterogeneity in mean and variance: applications to grade crossing safety analysis. Analytic Methods in Accident Research, 19, 33-48.

Hohenberger, C., Spörrle, M., Welpe, I. M., 2017. Not fearless, but self-enhanced: The effects of anxiety on the willingness to use autonomous cars depend on individual levels of selfenhancement. Technological Forecasting and Social Change, 116, 40-52.

Kang, L., Xiong, Y., Mannering, F.L., 2013. Statistical analysis of pedestrian perceptions of sidewalk level of service in the presence of bicycles. Transportation Research Part A, 53, $10-21$. 
Krueger, R., Rashidi, T. H., Rose, J. M., 2016. Preferences for shared autonomous vehicles. Transportation Research Part C, 69, 343-355.

Lavieri, P.S., Garikapati, V.M., Bhat, C.R., Pendyala, R.M., Astroza, S., Dias, F.F., 2017. Modeling individual preferences for ownership and sharing of autonomous vehicle technologies. Transportation Research Record, 2665, 1-10.

Mannering, F.L., Bhat, C.R., 2014. Analytic methods in accident research: Methodological frontier and future directions. Analytic Methods in Accident Research, 1, 1-22.

Mannering, F.L., Shankar, V., Bhat, C.R., 2016. Unobserved heterogeneity and the statistical analysis of highway accident data. Analytic Methods in Accident Research, 11, 1-16.

Mannering, F.L., 2018. Temporal instability and the analysis of highway accident data. Analytic Methods in Accident Research, 17, 1-13.

Masoud, N., Jayakrishnan, R., 2017. Autonomous or driver-less vehicles: Implementation strategies and operational concerns. Transportation Research Part E, 108, 179-194.

Menon, N., Barbour, N., Zhang, Y., Pinjari, A.R., Mannering, F., 2019. Shared autonomous vehicles and their potential impacts on household vehicle ownership: An exploratory empirical assessment. International Journal of Sustainable Transportation, 13(2), 111-122.

Muoio, D., 2017. A startup's \$1 million flying car is officially rolling out to buyers in 2020. Available at: https://www.businessinsider.com/aeromobil-1-million-flying-car-deliveriesbegin-2020-2017-4.

NASA., 2017. NASA Embraces Urban Air Mobility, Calls for Market Study. Available at: https://www.nasa.gov/aero/nasa-embraces-urban-air-mobility.

NASA., 2018a. NASA, Uber to Explore Safety, Efficiency of Future Urban Airspace. Available at: https://www.nasa.gov/press-release/nasa-uber-to-explore-safety-efficiency-of-future- 
urban-airspace.

NASA., 2018b. Taking Air Travel to the Streets, or Just Above Them. Available at: https://www.nasa.gov/aero/taking-air-travel-to-the-streets-or-just-above-them.

Opener., 2018. Opener Unveils First Canadian-Qualified Ultralight All-Electric Personal Aerial Vehicle. Available at: https://www.opener.aero/press/opener-unveils-first-canadianqualified-ultralight-all-electric-personal-aerial-vehicle/.

Oppitz, M., Tomsu, P., 2018. Future Technologies of the Cloud Century. Inventing the Cloud Century: 511-545.

Polzin, S.E., Chu, X., Godfrey, J., 2014. The impact of millennials' travel behavior on future personal vehicle travel. Energy Strategy Reviews, 5, 59-65.

Rocco, M., 2018a. Aston Martin reveals flying car that could hit $200 \mathrm{mph}$. Available at: https://www.foxbusiness.com/technology/aston-martin-reveals-flying-car-that-could-hit200-mph.

Rocco, M., 2018b. World's first flying car about to go on sale. Available at: https://www.foxbusiness.com/technology/worlds-first-flying-car-about-to-go-on-sale.

Rolls-Royce., 2018. The Rolls-Royce EVTOL project. Available at: https:/www.rollsroyce.com/media/our-stories/discover/2018/blue-sky-thinking-rr-unveils-evtol-conceptat-farnborough-airshow.aspx.

Russo, B.J., Savolainen, P.T., Schneider IV, W.H., Anastasopoulos, P.Ch., 2014. Comparison of factors affecting injury severity in angle collisions by fault status using a random parameters bivariate ordered probit model. Analytic Methods in Accident Research, 2, 2129.

Sacks, E., Ortiz, E., 2018. Uber introduces new safety features, including 911 access on its app. 
Available at: https://www.nbcnews.com/tech/innovation/uber-introduces-new-safetyfeatures-including-911-access-its-app-n865161.

Pantangi, S.S., Fountas, G., Sarwar, M.T., Anastasopoulos, P.Ch., Blatt, A., Majka, K., Pierowicz, J, Mohan, S., 2019. The Development of New Insights into Driver Behavior to Improve High Visibility Highway Safety Enforcement (HVE) Programs, Analytic Methods in Accident Research, 21, 1-12.

Sarwar, M.T., Anastasopoulos, P.Ch., Golshani, N., Hulme, K.F., 2017a. Grouped random parameters bivariate probit analysis of perceived and observed aggressive driving behavior: a driving simulation study. Analytic Methods in Accident Research, 13, 52-64.

Sarwar, M.T., Fountas, G., Anastasopoulos, P.Ch., 2017b. Simultaneous estimation of discrete outcome and continuous dependent variable equations: A bivariate random effects modeling approach with unrestricted instruments. Analytic Methods in Accident Research, 16, 23-34.

Sarwar, M.T., Fountas, G., Bentley, C., Anastasopoulos, P.Ch., Blatt, A., Pierowicz, J., Majka, K., Limoges, R., 2017c. Preliminary Investigation of the Effectiveness of High-Visibility Crosswalks on Pedestrian Safety Using Crash Surrogates. Transportation Research Record, 2659, 182-191.

Schmöller, S., Weikl, S., Müller, J., Bogenberger, K., 2015. Empirical analysis of free-floating carsharing usage: The Munich and Berlin case. Transportation Research Part C, 56, 3451.

Seraneeprakarn, P., Huang, S., Shankar, V., Mannering, F., Venkataraman, N., Milton, J., 2017. Occupant injury severities in hybrid-vehicle involved crashes: A random parameters approach with heterogeneity in means and variances. Analytic Methods in Accident 
Research, 15, 41-55.

Sheela, P. V., Mannering, F., 2019. The effect of information on changing opinions toward autonomous vehicle adoption: An exploratory analysis. International Journal of Sustainable Transportation, 1-13.

Sundström, A., 2011. The validity of self-reported driver competence: Relations between measures of perceived driver competence and actual driving skill. Transportation Research Part F, 14(2), 155-163.

Talebian, A., Mishra, S., 2018. Predicting the adoption of connected autonomous vehicles: A new approach based on the theory of diffusion of innovations. Transportation Research Part C, 95, 363-380.

Venkataraman, N., Shankar, V., Ulfarsson, G.F., Deptuch, D., 2014. A heterogeneity-in-means count model for evaluating the effects of interchange type on heterogeneous influences of interstate geometrics on crash frequencies. Analytic Methods in Accident Research, 2, 1220.

Unmanned Airspace, 2018. Urban air mobility takes off in 64 towns and cities worldwide. Available at: https://www.unmannedairspace.info/urban-air-mobility/urban-air-mobilitytakes-off-63-towns-cities-worldwide/

Washington, S., Karlaftis, M., Mannering, F.L., 2011. Statistical and Econometric Methods for Transportation Data Analysis. Chapman and Hall/CRC.

Xin, C., Guo, R., Wang, Z., Lu, Q., Lin, P.S., 2017. The effects of neighborhood characteristics and the built environment on pedestrian injury severity: a random parameters generalized ordered probability model with heterogeneity in means and variances. Analytic Methods in Accident research, 16, 117-132. 
Xu, X., Fan, C. K., 2018. Autonomous vehicles, risk perceptions and insurance demand: An individual survey in China. Transportation Research Part A, 124, 549-556. 